\title{
The FSP Boundary Science Driver Plan
}

T. D. Rognlien, D. G. Whyte, J. N. Brooks, J. M. Canik, M. Greenwald, D. P. Stotler, X. Tang, T. J. Tautges, B. D. Wirth

February 18, 2011 
This document was prepared as an account of work sponsored by an agency of the United States government. Neither the United States government nor Lawrence Livermore National Security, LLC, nor any of their employees makes any warranty, expressed or implied, or assumes any legal liability or responsibility for the accuracy, completeness, or usefulness of any information, apparatus, product, or process disclosed, or represents that its use would not infringe privately owned rights. Reference herein to any specific commercial product, process, or service by trade name, trademark, manufacturer, or otherwise does not necessarily constitute or imply its endorsement, recommendation, or favoring by the United States government or Lawrence Livermore National Security, LLC. The views and opinions of authors expressed herein do not necessarily state or reflect those of the United States government or Lawrence Livermore National Security, LLC, and shall not be used for advertising or product endorsement purposes.

This work performed under the auspices of the U.S. Department of Energy by Lawrence Livermore National Laboratory under Contract DE-AC52-07NA27344. 


\title{
The FSP Boundary Science Driver Plan
}

\author{
February 18, 2011
}

Fusion Simulation Project Boundary subcommittee

T.D. Rognlien (leader), Lawrence Livermore National Laboratory

D.G Whyte (deputy leader), Massachusetts Institute of Technology

J.N. Brooks, Purdue University

J.M. Canik, Oak Ridge National Laboratory

M. Greenwald, Massachusetts Institute of Technology

D.P. Stotler, Princeton Plasma Physics Laboratory

X. Tang, Los Alamos National Laboratory

T.J. Tautges, Argonne National Laboratory

B.D. Wirth, University of Tennessee 
This document was prepared as an account of work sponsored by an agency of the United States government. Neither the United States government nor Lawrence Livermore National Security, LLC, nor any of their employees makes any warranty, expressed or implied, or assumes any legal liability or responsibility for the accuracy, completeness, or usefulness of any information, apparatus, product, or process disclosed, or represents that its use would not infringe privately owned rights. Reference herein to any specific commercial product, process, or service by trade name, trademark, manufacturer, or otherwise does not necessarily constitute or imply its endorsement, recommendation, or favoring by the United States government or Lawrence Livermore National Security, LLC. The views and opinions of authors expressed herein do not necessarily state or reflect those of the United States government or Lawrence Livermore National Security, LLC, and shall not be used for advertising or product endorsement purposes.

This work performed under the auspices of the U.S. Department of Energy by Lawrence Livermore National Laboratory under Contract DE-AC52-07NA27344. 


\section{Outline}

\section{A. Background and motivation \\ B. Goals \\ C. Components:}

a. Requirements for physics codes (components) that need to be integrated in order to achieve the goals associated with the science driver.

b. Plans for adapting older components and as well as plans for developing new components.

\section{Framework requirements}

a. Analysis of the requirements for composition of the physics components (including data exchanges and algorithms)

b. Analysis of the requirements for the full workflow (task composition)

\section{E. Validation requirements}

a. Measurement requirements

b. Plans for validation of critical physics associated with the science driver

\section{F. Connections to other work}

a. Needs for collaboration with other efforts within the FSP

b. Requirements for work to be accomplished outside the FSP (foundational theory, SciDAC, etc.)

\section{G. Schedule and resources}

a. A projected schedule of the work to be carried over a 15 year time period

b. Realistic estimate of resources required

\section{H. Milestones}

a. Suggested high-level goals and milestones (perhaps at roughly the 2, 5, 10 and 15 year marks.)

\section{References}

\section{J. Appendix: Answers to FSP management committee's follow-on questions}




\section{Report}

\section{A. Background and motivation}

The boundary region in a fusion device includes a narrow region where plasma parameters change very rapidly and the near surface of adjoining materials know as plasma-facing components. Processes in this region determine the distribution of high levels of plasma exhaust particle and heat fluxes to surrounding materials and the associated response of the material (e.g., heating, erosion, and tritium trapping). Simultaneously, the eroded material becomes part of the ionized plasma and its intrusion into the hot core region must be understood and controlled. Issues associated with plasma exhaust, material erosion, tritium trapping, dust, and impurity intrusion are among the most challenging for the successful development of fusion via magnetic confinement devices focused on here, as well as inertia confinement devices. A predictive simulation model of this region requires coupling of a number of disparate physics models describing plasmas, neutral gas, radiation, solid and possibly liquid materials operating on a wide range of space and time scales.

The strong motivation to have predictive models of boundary region processes is summarized, e.g., by the recent ReNeW activity report [ReNeW 2009] and Fusion/ExascaleComputing Workshop [Exascale 2009]. These critical issues include: 1) lifetime of plasmafacing material components (estimates vary from hours to days to years), 2) unacceptable levels of tritium co-deposition in re-deposited material and tritium trapping in bulk surface material, 3 ) effect/limitations on the plasma including core plasma contamination by surface emitted material, 4) accumulation of dust that can be easily dispersed during an unintended vent, and 5) impact on additional core issues such as toroidal rotation, edge transport barrier, and tokamak density limits.

A brief characterization of the main physical processes in the boundary regions follows, beginning with the boundary plasma and continuing through to the surface material:

The behavior of the boundary plasma is strongly influenced by changing topology of confining magnetic field, $\mathbf{B}$, from being composed of closed fields lines to open fields lines that intersect material surfaces; the poloidal magnetic flux surface where this transition occurs is called the separatrix. The region outside the separatrix is called the scrape-off layer (SOL). Because of the much more rapid parallel plasma transport along B than across it, most of the heat and particle fluxes are concentrated on flux surfaces that map along $\mathbf{B}$ to the near the separatrix. Consequently, the SOL plasma is thin, yielding large radial gradients, can have substantial poloidal variations, and a range of collisional parallel mean-free paths to scale lengths. These features distinguish the SOL plasma from that in the core, and the gradients are a potential source of strong plasma instabilities, including short wavelength microinstabilities and long wavelength edge localize modes (ELMs), that impact particle and energy dispersal to surfaces.

A substantial neutral particle component typically exists in the SOL owing to plasmamaterial interactions (PMI) yielding recycled main fuel hydrogenic (deuterium and tritium, DT, ) atoms and molecules, and neutral sputtering wall impurities via physical or chemical mechanisms as discussed below. Owing to the lower electron temperatures in the SOL, neutrals can penetrate some distance into the plasma volume before being ionized, providing refueling and contamination mechanisms for the core plasma. Strong recycling can substantially lower the plasma temperature and increase in plasma density and radiation near material surfaces, especially in the divertor region. Neutral penetration across the separatrix may play a role in the 
H-mode pedestal [Park 2007] formation. Plasma chemistry can also play an important role, especially for carbon-base devices where neutral chemically sputtered particles are usually in the form of hydrocarbons (e.g., $\mathrm{HC}_{4}$ ) that are subsequently broken down into their constitutive elements by the plasma.

Excitation, ionization, and recombination processes can produce a substantial energy-loss mechanism via line radiation that broadens the total heat-flux profile. The atomic rates can depend on plasma density, temperature, and local transport that involve detailed atomic physics models. The impurity density is generally low enough that the plasma is optically thin to impurity radiation, but the hydrogen atom densities may be high enough that emitted photons, especially Lyman- $\alpha$, can be reabsorbed before escaping the divertor [Post 1995]. The resulting photon trapping not only affects the distribution and spectrum of emitted radiation, it alters the ionization balance for the atoms [Reiter 2007]. The light emitted by neutral atoms, regardless of their origin, is the basis for a wide variety of important diagnostic techniques.

The boundary between the gaseous SOL and the solid material or radio frequency (RF) antenna is the plasma sheath. The sheath controls the energy and angle of incidence of impinging ions from the plasma, including re-deposited surface material ions. Most of the impinging ion energy is acquired in the sheath. For the tokamak divertor type, with highly oblique strong magnetic field incidence to the surface (order of $1-2^{\circ}$ ), the sheath consists of a Debye sheath, of order $10 \mu \mathrm{m}$, and a magnetic sheath, of order of 3 times the D-T ion gyroradius, or $\sim 1 \mathrm{~mm}$. Average angles of incidence for D-T ions are about $50^{\circ}$ from the surface normal, such angles generally involving a major enhancement of sputter yields over normal incidence. Plasma currents and surface roughness can play important roles in the sheath characteristics as well [Ryutov 1996].

Understanding and managing plasma/material interactions are probably the most critical issues for fusion technology [Federici 2001]. Basic processes can be separated into those that occur in the near-surface region, say the first tens of microns, and those that occur throughout the bulk. The near-surface region is the focus here where the impinging plasma and neutrals contribute, while the bulk properties are impacted by deeply penetrating neutrons and thermal excursions. The fundamental processes of backscattering and sputtering are understood theoretically for well-characterized materials (e.g., binary collision models for backscattering and physical sputtering [Eckstein 1991], and molecular dynamics for chemical sputtering [Nordlund 2006]) and are able to reproduce data from laboratory experiments. Likewise, there are basic models for migration and trapping of hydrogenic species within materials [Hillis 2001, Pigarov 2009]. However, surface materials in fusion are reprocessed in that substantial gross erosion and re-deposition occurs, resulting in irregular surfaces with complex structure. In devices with mixed materials (e.g., ITER with Be walls and $\mathrm{C}$ or $\mathrm{W}$ divertor plates), the surface composition itself is uncertain. Development of adequate models to understand and predict the behavior of such material surfaces is in its infancy. It is important to move beyond qualitative models that require empirical coefficients to more physics-based simulations, which will require a substantial increase in funding.

Practical considerations, based on tritium retention, fuel inventory and erosion management, lead to a design preference for the use of tungsten as the divertor material, and possibly also the entirety of the plasma facing components, in future fusion reactors. In fact, the 'all metal' ITER design option involves replacing the current graphite design with tungsten strike points that would operate at temperatures above $1000 \mathrm{~K}$. In such environments, tungsten will experience 
high heat loads and exposure to various hydrogen and helium isotopes and impurity species, possibly including beryllium, carbon and argon (which is added to enhance radiative plasma losses). To date, only limited experience exists with solid tungsten in magnetic fusion confinement devices, while recent laboratory based plasma exposure experiments involving hydrogen and helium implantation on tungsten have demonstrated a very rich, and as yet poorly understood surface response behavior.

Finally, the response of the SOL and especially wall materials to transient events such as edge localized modes (ELMs) and disruptions (including vertical displacements) must be understood. In addition, the interaction the boundary plasma and material with radio frequency (RF) antennas, and associated electromagnetic fields, requires much better integration into boundary models. For controllable ELMs, the main issue is what defines acceptable ELM characteristics in terms of size, duration, and frequency to avoid excessive material erosion. For disruptions, the location and damage to materials from high heat flux including runaway electrons needs quantification. RF sources inject power into the SOL plasma and drives potentially large RF sheaths, and in turn, the plasma gives rise to antenna sputtering. All of these transient and RF processes produce supra-thermal particles and thus ultimately require kinetic descriptions in 3D.

\section{B. Goals}

The survivability of fusion plasma facing materials places constraints on the impinging plasma fluxes. A boundary plasma model capable of predicting those fluxes will allow future devices to be designed and operated in a manner consistent with those constraints. Such a model should, first, be able to reproduce the parametric scaling of the following quantities in existing experiments, and, second, incorporate a fundamental understanding of the underlying physical processes, allowing the model to be extrapolated to future devices with confidence.

- Heat loads to material surfaces both during steady state operation (in L-mode and H-mode between ELMs) and in transients (ELMs, disruptions)

- Fluxes of particles to material surfaces, including those of deuterium, tritium, helium, and all impurities.

- Fluxes of particles back into the boundary plasma due to plasma-material interactions, including:

- Impurity generation by physical and chemical sputtering,

- Recycling of deuterium and tritium,

- Removal of deuterium, tritium, helium and other particles from the system by pumping mechanisms.

- Transport of those particles through the boundary plasma and the resulting sources of particles, momentum, and energy in the pedestal and core plasma.

- Tritium recycling, transport, and retention in materials; implicit in the above, but listed separately because of its importance.

- Particle, momentum, and energy sources in the boundary and core plasma due to external fueling, including gas puffing, pellets, and other techniques.

- Modification of plasma facing materials due to plasma fluxes and externally applied treatments (e.g. boronization), including erosion, re-deposition with mixed materials, dust 
generation (and transport).

\section{Components:}

a. Requirements for physics codes (components) that need to be integrated in order to achieve the goals associated with the science driver.

The basic physics equations used in the models for plasma, neutrals, and photons, either fluid or kinetic, are usually differential equations of either the Eulerian or Lagrangian form. The plasma Eulerian or continuum models are multi-dimensional partial differential equations with convection and diffusion operators plus source terms - akin to Navier-Stokes equations in fluid dynamics. The Lagrangian or particle formulation describes the trajectories of a large ensemble of particles or fluid elements in response to various forces. Each type of model for charged particles also includes an Eulerian field equation for the electrostatic potential (Poisson's equation or a current continuity equation) and sometimes the magnetic field typically using reduced Maxwell equations. Kinetic codes that compute the velocity space distribution function require a model for collisional processes, which in the case of nearly fully ionized plasma, is the 2nd order differential operator (convection and diffusion in velocity space) Fokker-Planck equation for charged-particle collisions. Sometimes models reduce the size of the problem by averaging over one or more of the dimensions, a procedure that can result in integro-differential equations to describe nonlocal processes.

Table 1. Requirements for Boundary SOL plasma models

\begin{tabular}{|c|c|c|c|}
\hline Model & Capability & Space/time scales & Input/output \\
\hline $\begin{array}{c}\text { Magnetic } \\
\text { equilibrium, } \\
\text { mesh, and wall } \\
\text { position/ } \\
\text { composition }\end{array}$ & $\begin{array}{l}\text { Provides magnetic flux } \\
\text { surfaces for mesh } \\
\text { construction and B-field } \\
\text { components }\end{array}$ & $\begin{array}{l}\text { Usually 2D axisymmetric; } \\
\text { may include 3D perturbation; }\end{array}$ & $\begin{array}{l}\text { In: Coil and plasma } \\
\text { current/pressure. Also } \\
\text { wall geometry } \\
\text { Out: flux-surfaces in } \\
\text { (R,Z) leading to mesh } \\
\text { conforming to } \\
\text { divertor/wall }\end{array}$ \\
\hline $\begin{array}{l}\text { Transport - } \\
\text { fluid }\end{array}$ & $\begin{array}{l}\text { Yields plasma profiles \& } \\
\text { flows via fluid eqns for } \\
\text { e, D, T, multi-charge- } \\
\text { state impurities; couple } \\
\text { to neutrals; electrostatic } \\
\text { potential }\end{array}$ & $\begin{array}{l}\text { 2D with toroidal symmetry, } \\
\text { or } 3 \mathrm{D} \text {; from pedestal to wall } \\
\text { and divertor at arbitrary angle } \\
\text { to magnetic flux surfaces; } \\
\text { Time } 10^{-8} \text { s (elec. \| conduc.); } \\
\sim 0.1 \mathrm{~ms} \text { (ELM crash); } 1 \mathrm{~ms} \\
\text { (blobs); } 10 \text { 's ms (btwn ELM } \\
\text { cycle); to steady state }\end{array}$ & $\begin{array}{l}\text { In: Magnetic field, mesh, } \\
\text { anomalous fluxes, atomic } \\
\text { rates, power from core, } \\
\text { wall conditions } \\
\text { Out; 2D plasma profiles } \\
\text { of density, momentum, } \\
\text { and energy }\end{array}$ \\
\hline
\end{tabular}




\begin{tabular}{|c|c|c|c|}
\hline $\begin{array}{l}\text { Transport - } \\
\text { kinetic }\end{array}$ & $\begin{array}{l}\text { Adds kinetic effects to } \\
\text { fluid transport along and } \\
\text { across B-field; computes } \\
\text { distribution function; e, } \\
\text { D initially, then } \\
\text { impurities, T, and couple } \\
\text { to neutrals; electrostatic }\end{array}$ & $\begin{array}{l}2 \mathrm{D} \text { axisymmetric } \\
\text { configuration, } 2 \mathrm{D} \text { velocity } \\
\text { spaces; from pedestal to } \\
\text { wall/divertor; Time } \sim 10^{-9}-10^{-7} \\
\mathrm{~s} \text { (e-i grid transit) } \sim 10^{-7}-10^{-5} \mathrm{~s} \\
\text { (e-i bounce times); + fluid } \\
\text { scales }\end{array}$ & $\begin{array}{l}\text { In: Magnetic field, mesh, } \\
\text { anomalous fluxes, atomic } \\
\text { rates, power from core, } \\
\text { wall conditions } \\
\text { Out; 2D plasma profiles } \\
\text { of density, momentum, } \\
\text { and energy, adds 2D } \\
\text { velocity space particle } \\
\text { distribution functions }\end{array}$ \\
\hline $\begin{array}{l}\text { Turbulence - } \\
\text { fluid }\end{array}$ & $\begin{array}{l}\text { Evolves drift-type } \\
\text { instabilities to find } \\
\text { nonlinear steady-state } \\
\text { turbulence \& associated } \\
\text { anomalous transport; e, } \\
\text { D initially, then } \\
\text { impurities, T, and couple } \\
\text { to neutrals; electrostatic, } \\
\text { magnetic fluctuations }\end{array}$ & $\begin{array}{l}3 \mathrm{D} \text {; from pedestal to } \\
\text { wall/divertor; Time - sub } \\
\text { drift-wave and maybe Alfven } \\
\text { wave }\left(\sim 10^{-7} \mathrm{~s}\right) \text {; saturation } \\
\sim 0.3 \mathrm{~ms}\end{array}$ & $\begin{array}{l}\text { In: Magnetic field, mesh, } \\
\text { initial plasma profiles, } \\
\text { core, wall boundary } \\
\text { conditions } \\
\text { Out; 3D plasma } \\
\text { fluctuation levels and } \\
\text { turbulent fluxes; often } \\
\text { average toroidally for } \\
\text { interpretation \& coupling } \\
\text { to transport }\end{array}$ \\
\hline $\begin{array}{l}\text { Turbulence - } \\
\text { kinetic }\end{array}$ & $\begin{array}{l}\text { Adds kinetic effects to } \\
\text { fluid turbulence for e, D } \\
\text { initially, then impurities, } \\
\mathrm{T} \text {, and couple to neutrals; } \\
\text { electrostatic, magnetic } \\
\text { fluctuations }\end{array}$ & $\begin{array}{l}\text { 3D configuration, } 2 \mathrm{D} \text { velocity } \\
\text { spaces; from pedestal to } \\
\text { wall/divertor; Time, similar to } \\
\text { kinetic transport }\end{array}$ & $\begin{array}{l}\text { In: Magnetic field, mesh, } \\
\text { initial plasma profiles, } \\
\text { core, wall boundary } \\
\text { conditions } \\
\text { Out; 3D plasma } \\
\text { fluctuation levels and } \\
\text { turbulent fluxes; velocity- } \\
\text { space distribution }\end{array}$ \\
\hline Sheath model & $\begin{array}{l}\text { Computes thin } \\
\text { electrostatic sheath } \\
\text { separating plasma and } \\
\text { materials }\end{array}$ & $\begin{array}{l}\text { 2D, 3D configuration and } \\
\text { 3D ion, 2D electron velocity } \\
\text { space; inclined B-field; later } \\
\text { rough surfaces; Time - } \\
\text { plasma frequency, ion } \\
\text { cyclotron frequency }\end{array}$ & $\begin{array}{l}\text { In: Magnetic field, mesh, } \\
\text { plasma profiles, wall } \\
\text { material } \\
\text { Out; 1D or 2D magnetic } \\
\text { and Debye sheath } \\
\text { structure }\end{array}$ \\
\hline
\end{tabular}

For neutrals, ballistic particle trajectories between collisions are much simpler than for the plasma owing the absence of electromagnetic forces. The nature of collisions is more varied and often very dominant. Chief among collision processes are prompt charge-exchange with ions and ionization/recombination/excitation producing nonlocal transport in velocity space. Neutral-neutral collisions require another (nonlinear) model. As for the plasma, both fluid and kinetic descriptions can be used with the kinetic model most rigorous, but also costly. The most common kinetic approach is Monte Carlo. At a numerical model level, photon 
transport is very analogous to that of neutrals. Both neutral and photon transport depend on atomic cross-sections that are usually included as a table lookup function with interpolation between values as a function of particle energy and density. For dense plasmas, excited states become an important complication.

Table 2. Requirements for Boundary SOL neutral, photon, dust, and atomic physics models

\begin{tabular}{|c|c|c|c|}
\hline Model & Capability & Space/time scales & Input/output \\
\hline $\begin{array}{c}\text { Fluid } \\
\text { transport }\end{array}$ & $\begin{array}{l}\text { Determines neutral } \\
\text { species profiles in the } \\
\text { plasma; (in order) D } \\
\text { density \& flow, impurity } \\
\text { atoms, D temperature, } \mathrm{D}_{2} \\
\text { density, } \mathrm{T} \text { (generalize to } \\
\text { all isotopes) }\end{array}$ & $\begin{array}{l}2 \mathrm{D} \text { axisymmetric, extend } \\
\text { mesh to walls to allow } \\
\text { accurate PMI, } 3 \mathrm{D} \text { (if needed); } \\
\text { Time, }>10^{-7-} 10^{-6} \mathrm{~s}(\mathrm{CR} \\
\text { validity, grid transit) }\end{array}$ & $\begin{array}{l}\text { In: Plasma profiles, wall } \\
\text { geometry and albedo, } \\
\text { recycling coeff. } \\
\text { Out; 2D or 3D profiles of } \\
\text { neutrals in the SOL, core }\end{array}$ \\
\hline $\begin{array}{l}\text { Kinetic } \\
\text { transport }\end{array}$ & $\begin{array}{l}\text { Adds kinetic effects to } \\
\text { fluid model - long mean- } \\
\text { free path; Initially: } \mathrm{H} \text { (all } \\
\text { isotopes), } \mathrm{H}_{2}, \mathrm{H}_{2}+ \\
\text { impurity atoms; then: } \\
\text { nonlinear } \mathrm{H} \& \mathrm{H}_{2}, \mathrm{H}_{2}(\mathrm{v}) \\
\text { (and associated species), } \\
\text { impurity molecules, (on } \\
\text { faster time scales, or if } \\
\text { required by radiation } \\
\text { trapping) } \mathrm{H}(\mathrm{n}), \mathrm{H}_{2}(\mathrm{n}, \mathrm{v})\end{array}$ & $\begin{array}{l}\text { 2D axisymmetric, 3D; Time, } \\
>10^{-7-} 10^{-6} \mathrm{~s}(\mathrm{CR} \text { validity, } \\
\text { grid transit) }\end{array}$ & $\begin{array}{l}\text { In: Plasma profiles, wall } \\
\text { and pump geometry, } \\
\text { recycling, backscatter } \\
\text { rates, material } \\
\text { composition } \\
\text { Out; 2D or 3D profiles of } \\
\text { neutrals in the SOL, core; } \\
\text { CX-fluxes to walls }\end{array}$ \\
\hline $\begin{array}{l}\text { Photon } \\
\text { transport }\end{array}$ & $\begin{array}{l}\text { Determine how released } \\
\text { photons escape the } \\
\text { plasma/neutrals; } \\
\text { Ly- } \alpha \text { (escape } \\
\text { probability), Ly- } \alpha \\
\text { (Doppler \& Stark } \\
\text { broadened, Zeeman } \\
\text { splitting), Ly- } \alpha \text { (add } \\
\text { anisotropic line shape, } \\
\text { fine structure), Ly- } \alpha \text {, add } \\
\text { lines for T, and other } \\
\text { lines as needed. }\end{array}$ & $2 \mathrm{D}$ axisymmetric, 3D & $\begin{array}{l}\text { In: Neutral and plasma } \\
\text { profiles, wall geometry, } \\
\text { Out; Re-adsorption and } \\
\text { emission of photons; 2D } \\
\text { or 3D profiles of photon } \\
\text { flux to walls }\end{array}$ \\
\hline
\end{tabular}




\begin{tabular}{|l|l|l|l|}
\hline Dust transport & $\begin{array}{l}\text { Traces trajectories and } \\
\text { ablation of dust particles } \\
\text { in SOL; macroscopic } \\
\text { particles of wall } \\
\text { material, e.g., C, W, Be; } \\
10 \mathrm{~nm} \text { to } 100 \mu \mathrm{m} \text { in size; } \\
\text { negative charge; ablation } \\
\text { requires plasma model } \\
\text { radiation loss }\end{array}$ & $\begin{array}{l}\text { 3D trajectory throughout } \\
\text { SOLime, 10's of msec }\end{array}$ & $\begin{array}{l}\text { In: Dust source, B-field, } \\
\text { plasma and potential } \\
\text { profiles, wall geometry, } \\
\text { Out; 3D distribution of } \\
\text { dust particles in SOL } \\
\text { including flux across } \\
\text { separatrix }\end{array}$ \\
\hline Atomic rates & $\begin{array}{l}\text { Provides, relevant to the } \\
\text { above, cross sections } \\
\text { (differential where } \\
\text { needed) and kinetic data } \\
\text { for reaction products, } \\
\text { collisional radiative } \\
\text { models for transport time } \\
\text { scale simulations, } \\
\text { especially for hydrogen } \\
\text { atoms \& molecules; } \\
\text { tractable models for } \\
\text { high-Z atoms and } \\
\text { hydrocarbon breakup. }\end{array}$ & $\begin{array}{l}\text { (Desolved in collisional } \\
\text { radiative models) }\end{array}$ & $\begin{array}{l}\text { In: Electron temperature } \\
\text { and density } \\
\text { Out; atomic rates } \\
\text { averaged over } \\
\text { Maxwellian for fluid } \\
\text { models or differential } \\
\text { cross-sections for kinetic } \\
\text { codes }\end{array}$ \\
\hline
\end{tabular}

For the material surfaces, the basic physics equations used are of the general type described above, though here particle methods are more common. The most fundamental model of the material is Molecular Dynamics where individual projectiles are followed in the electrostatic potential of the lattice structure of the material, breaking bonds between lattice elements and reforming a new arrangement, which can result in the ejection of a lattice atom into the vacuum (sputtering).

Table 3. Requirements for Boundary material models

\begin{tabular}{|l|l|l|l|}
\hline Model & Capability & Space/time scales & Input/output \\
\hline
\end{tabular}




\begin{tabular}{|c|c|c|c|}
\hline $\begin{array}{c}\text { Basic } \\
\text { backscattering/ } \\
\text { sputtering rates }\end{array}$ & $\begin{array}{l}\text { Determines PMI rates } \\
\text { for various process; } \\
\text { Energy and angular } \\
\text { resolved backscattering } \\
\text { \& physical sputter } \\
\text { yields; backscattered \& } \\
\text { sputtered velocity } \\
\text { distributions for H, Be, } \\
\text { C, Mo, selected C } \\
\text { chemical sputter yields }\end{array}$ & $\sim 0-10 \mathrm{~nm}$; Time, $1 \mathrm{ps}$ & $\begin{array}{l}\text { In: Incident ion energy, } \\
\text { mass, and angle to surface } \\
\text { Out; backscatter and } \\
\text { sputtering rates }\end{array}$ \\
\hline $\begin{array}{l}\text { Hydrogen } \\
\text { transport }\end{array}$ & $\begin{array}{l}\text { Computes hydrogen } \\
\text { transport, trapping, and } \\
\text { release from materials; } \\
\text { T co-deposition rates as } \\
\text { a function of surface } \\
\text { temperature, other T } \\
\text { trapping }\end{array}$ & $\sim 0-10 \mathrm{~nm}$ & $\begin{array}{l}\text { In: Material, temperture, } \\
\text { possible defects/traps, } \\
\text { transport coefficients, initial } \\
\text { H concentration, incident H } \\
\text { flux } \\
\text { Out; Profile of H into the } \\
\text { material, number releasable }\end{array}$ \\
\hline Re-deposition & $\begin{array}{l}\text { Provides location and } \\
\text { rate of re-deposition of } \\
\text { previously sputtered } \\
\text { material for all } \\
\text { candidate surface } \\
\text { materials }\end{array}$ & $\begin{array}{l}\sim 0-1 \mathrm{~cm} ; \text { Time, } \sim 0-10 \\
\mu \mathrm{s}\end{array}$ & $\begin{array}{l}\text { In: Plasma fluxes and } \\
\text { profiles, sputtering rates, } \\
\text { surface material \& } \\
\text { temperature, B-field } \\
\text { Out; location and rate of } \\
\text { impurity flux back to surface }\end{array}$ \\
\hline $\begin{array}{c}\text { Material } \\
\text { evolution/ dust } \\
\text { production }\end{array}$ & $\begin{array}{l}\text { Describes how surface } \\
\text { materials evolve from } \\
\text { strong plasma fluxes; } \\
\text { Mixed materials (e.g. } \\
\text { Be/W, C/W) } \\
\text { formation/plasma } \\
\text { interaction properties; } \\
\text { He/W micro-structural } \\
\text { evolution and response; } \\
\text { dust composed of } \\
\text { loosely bound } \\
\text { macroparticles }\end{array}$ & $\begin{array}{l}\text { Microscopic } \\
\text { processes: 0-10 nm; } \\
\text { Macroscopic } \\
\text { processes, e.g., dust } \\
\text { production up to } \\
100 \mu \mathrm{m} \text {; Time, } \sim 1 \mathrm{~ns}- \\
1000 \mathrm{~s}\end{array}$ & $\begin{array}{l}\text { In: Location and rate of } \\
\text { impurity fluxes to surface, } \\
\text { temperature } \\
\text { Out; Evolution of surface } \\
\text { including composition }\end{array}$ \\
\hline
\end{tabular}

b. Plans for adapting older components and as well as plans for developing new components.

\section{1) Plasma transport}

Several codes exist capable of calculating plasma transport in the pedestal and SOL in the fluid approximation for long, transport time scales (excluding calculation of the 
turbulent transport itself). The most common of the 2-D codes, which were developed for tokamak applications and thus assume axisymmetry, are UEDGE [Rognlien 94] and SOLPS [Schneider 06] although other codes have been developed for application to specific tokamaks (e.g., EDGE2D [Simonini 94] and KTRAN [Kim 05]). For a fluid transport FSP component, all of these codes have the basic features desired, but do differ in a number of deals, including solution algorithms. UEDGE is developed in the U.S. and is a component in FACETS, but has focused (not limited to) on coupling to fluid neutrals and only occasionally Monte Carlo neutrals. SOLPS is being developed in the EU has a larger development team (often postdocs/students), and has focused on coupling to Monte Carlo neutrals. SOLPS is in use in the U.S., but there is limited experience with code details.

Kinetic transport codes for the boundary region have and are being developed that solve for the 2-D velocity space particle distribution functions under the assumption that the third gyrophase velocity coordinate can be averaged over. Models assuming only 1-D spatial variation along $\mathbf{B}$ have been developed and performed a number of test problems [Batishchev 1997; Matte 1988]; here careful attention was given to the Fokker-Planck collision operator. More recent codes have added a second spatial dimension assuming toroidal symmetry and either use a particle-in-cell method [Chang 2004] or a continuum method where the distribution function is represented on a 4-D grid [Xu 2007]. While these latter codes include neoclassical drift-orbit effects, the collision operators have not been stressed for collisional SOL plasmas and this highlights an important area that needs further development, i.e., a 4-D kinetic transport code with an accurate and efficient collision module. The FSP should be able to leverage the kinetic transport work started in CPES (XGC0 [Chang 2004]]) and ESL (TEMPEST [Xu 2007], COGENT [Dorr 2010]). A key need here is Fokker-Planck collision model capable of truly spanning the long-toshort mean free path regimes found in the SOL.

\section{2) Plasma turbulence}

Plasma turbulence in the SOL is a difficult problem owing to the large amplitude and thus highly nonlinear physics involved. Most progress has been made with two-fluid (ion and electron) models. There are 2-D models in simplified geometry that show some of the basic characteristics of the SOL microturbulence [Garcia 2003; Russell 2009]. Here the detail magnetic geometry and thus strong magnetic shear is not included, and the third spatial coordinate is represented by an eikonal approximation for the wave variation. The most general fluid model that includes the full tokamak toroidal geometry with magnetic shear and the divertor plates is the 3-D BOUT code [Xu 2009]. An advanced, flexible version based on the BOUT code (called BOUT ++ ) has recently been developed using on the $\mathrm{C}++$ programming language [Dudson 2009]. BOUT ++ has also been used recently to model ELMs [Xu 2010]. While some kinetic 5-D turbulence simulations have been performed using XGC1, that modeling has focused on the region inside the separatrix.

For fluid turbulence, BOUT ++ is well suited for the SOL and is the only known code to include some region inside the separatrix, with the exception of a developing effort in France. BOUT ++ is relatively mature having being a major rewrite in $\mathrm{C}++$, but using many of the same algorithmic pieces from the original BOUT. Further, BOUT ++ is an open-source code being developed both in the U.S. and the U.K. For kinetic turbulence, 
we again look to the CPES and ESL projects, though such 5D simulations are in their early stages at best.

\section{3) Neutral transport}

The implementation of detailed atomic and PMI physics models is most straightforward in a kinetic, Monte Carlo neutral transport code. Two widely used codes of this type are EIRENE and DEGAS 2. The Monte Carlo algorithm also allows the experimental geometry to be replicated in as much detail as is desired. The principal drawbacks to the Monte Carlo approach are the statistical noise in the results and the computational resources required to simulate short mean free path regimes. Because the Monte Carlo algorithm parallelizes naturally, the severity of both of these is mitigated by the continued increase in the number of CPUs available for production calculations.

The particular code which should be developed into the kinetic neutral transport component is not clear. EIRENE contains more physics than DEGAS 2 and is more widely used. On the other hand, no development support for it is available within the US fusion community. With sufficient manpower, the physics capabilities of DEGAS 2 can be brought up to the same level as those in EIRENE. However, the computational tasks undertaken by these codes can be neatly broken down into flexible, easily extended "objects". Consequently, a third option of developing a new code becomes viable if a programming language and development environment or framework can be identified that allows this representation to be straightforwardly implemented.

Fluid neutral transport models suffer from neither of the shortcomings of kinetic Monte Carlo, but are more restricted in the level of physics detail that can be incorporated into the calculations. Because fluid neutral models provide a precise, albeit approximate, neutral density profile for a given plasma, they are typically the default treatment of neutrals in fluid plasma transport codes, such as SOLPS/B2 and UEDGE. The absence of statistical noise in the neutral solution also permits an implicit approach to solving the coupled plasma - neutral equations, allowing the tight coupling associated with the charge exchange process to be handled efficiently.

A hybrid fluid-kinetic neutral transport model would treat short mean free path regions efficiently while retaining fully detailed kinetic behavior elsewhere. Although algorithms for such a hybrid model have been contemplated [Karney 1998], viable implementations do not yet exist. Likewise, methods for substantially reducing statistical noise in Monte Carlo calculations (correlated sampling, quasi-Monte Carlo, backward Monte Carlo) have been developed for other applications, but have not been incorporated into fusion neutral transport codes.

\section{4) Radiation transport}

The inclusion of radiation transport increases the complexity of a divertor transport simulation since plasma, neutrals, and radiation are tightly coupled and must be computed consistently. Moreover, all processes impacting the photon line shapes (Doppler and Stark broadening, Zeeman splitting) should be included [Reiter 2007]. The similarity between the neutral and radiation transport equations facilitated the incorporation of the latter into the EIRENE Monte Carlo transport code with straightforward extensions [Reiter 2007, Kotov 2006]. An alternative, approximate approach utilizes effective collisional radiative rates for hydrogen ionization and recombination having an additional dependence on an optical depth parameter 
characterizing the distance to the material boundary weighted by the neutral density along that path [Scott 2004]. These rates were obtained by incorporating a simplified, partially ionized, plasma transport model into the non-linear thermodynamic equilibrium radiation transport code CRETIN [Adams 2004] and can be easily incorporated into existing plasma and neutral transport codes [Scott 2004]. Because of the relatively high opacity of detached plasmas, an approximate treatment of this sort may suffice [Kotov 2006].

\section{5) Dust}

Dust production and transport has been recognized as a safety concern for fusion devices owing to its potential role in tritium retention, impurity transport and ease of mobilization during a vent. All present tokamaks produce some level of dust, but the amount is projected to increase very substantially with long-running devices such as ITER and beyond. Most theory/modeling progress has been made in understanding the mobilization and ablation of dust during a plasma discharge via the use of the macroscopic particle model DUSTT [Pigarov 2005] using a stationary UEDGE plasma background. More recently, DUSTT has been dynamically coupled to UEDGE [Smirnov 2010]. The DUSTT is the most advanced transport model known and should provide a good starting point for further work within the FSP. On the other hand, the production of dust is much less understood and here models need to be developed.

\section{6) Sheath}

There are existing codes, e.g. BPHI-3D [Brooks et al. $\mathrm{xxx}$ ] for computation of sheath parameters and ion transport for a 3-D, tokamak geometry (near-tangential B-field), timeindependent sheath. One need is for inclusion of RF induced sheath models/codes for plasma facing surface response.

\section{7) Sputtering and transient response in materials, including D-T transport/accumulation}

This topic area includes a number of strongly interacting effects, and thus the models used are discussed under this one subsection.

Plasma/material response has been the subject of 20+ years of analysis and model and code development (inasmuch as plasma facing component performance/lifetime is probably the single most technology feasibility issue for fusion power). There do exist code packages for the steady state response, in particular the REDEP/WBC sputtering erosion/re-deposition code package [Brooks 2002, 2009], and the transient response HEIGHTS code package [Hassanein 2002, 2003, 2009]. These two packages include numerous sub codes for sputter yield, bulk material response, tritium trapping, and related areas e.g. as summarized in [Exascale 2009]. Briefly, the REDEP/WBC package computes the $(3 \mathrm{D}, 3 \mathrm{v})$ kinetic, sub-gyro-orbit transport of sputtered (and thermally etc. emitted) impurities within a few ion gyro-radii of the surface (atoms and ions), while farther into the plasma; it uses a guiding-central $(2 \mathrm{v})$ ion model. The resulting surface response is simulated, including mixed-material evolution and tritium co-deposition. HEIGHTS computes the material response to transient events like ELMs, disruptions, Vertical Displacement Events, and associated runaway electrons. HEIGHTS can treat the 3D cases, including vapor formation, radiation transport, and surface thermal evolution. Both REDEP/WBC and HEIGHTS have been extensively developed, including some parallelization, and could be used in their existing state. REDEP/WBC has been coupled with a UEDGE SOL simulation, but to date only via a manual iteration cycle [Brooks] 
The REDEP/WBC and HEIGHTS sub-codes/packages could also supply important components to be combined with others in the FSP.

Comparatively recently, another code called WallPSI [Pigarov 2009] has been developed to consider the dynamics and meso-scale transport of hydrogenic species in carbon and beryllium. This code computes the recycling and sputtering of material in response to plasma/neutral fluxes, and solves for the dynamic temperature hydrogenic content of the material. WallPSI presently provides the wall model for the FACETS project [Cary 2009].

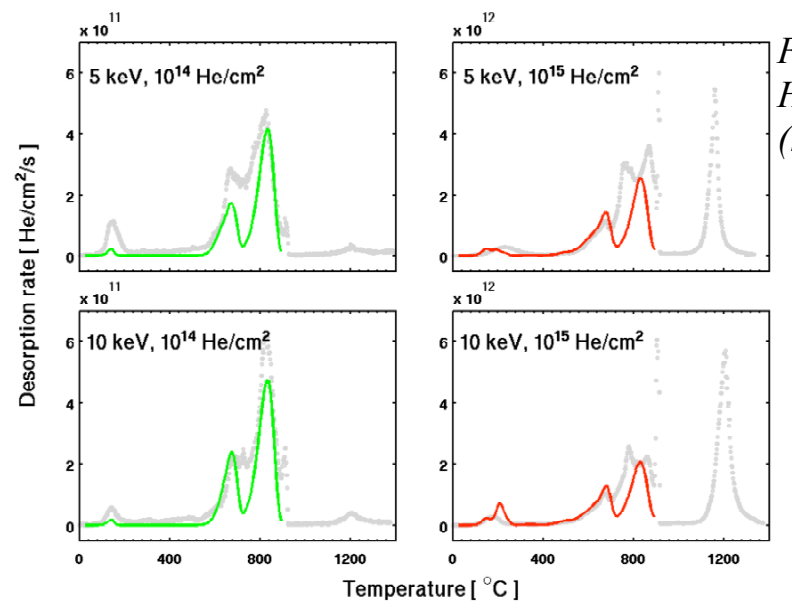

Fig. 1. Cluster dynamics simulation of Hydrogen desorption for different temperatures (needs explanation).

At a more fundamental, and therefore shorter timescale, other codes are exploring the material behavior at the atomistic level and pioneering ways to couple such results to more macroscopic, long timescale models. For example, the application of the codes based on Molecular Dynamics (AMD, LAMPPS, MDCASK, etc. by A. Voter, LANL, P.

Krstic, ORNL, J. Marian, LLNL, etc.) as well as Kinetic Monte Carlo, and Cluster dynamics (TRIM, PARASPACE, PLEXIES by J.P Allain, Purdue, B. Wirth, UTenn) approaches were able to explain important experimental data on the sputtering of mixed materials; chemical erosion and hydrogen desorption from carbon, and helium dynamics in tungsten (e.g. see Fig. 1). Simulation of pores in tungsten caused by He irradiation and formation of bubbles [Sharafat 2009] shows a good agreement with experimental observations. A basic visco-elastic model of the "fuzz" growth for tungsten material in plasma containing helium reproduces major experimental finding [Krasheninnikov 2010].

\section{Framework requirements}

a. Analysis of the requirements for composition of the physics components (including data exchanges and algorithms)

Because the boundary region includes a number of strongly interacting species and processes, coupling of different elements is essential to obtain a predictive model. While some existing codes combine different elements in a type of direct coupling, e.g., fluid plasma and neutral components may be solved simultaneously on the same mesh, here we consider coupling between the most basic physics elements.

Table 4. Requirements for coupling components

\begin{tabular}{|l|c|c|c|}
\hline Coupling & $\begin{array}{c}\text { Particle } \\
\text { species/fields }\end{array}$ & $\begin{array}{c}\text { Type, size, frequency of } \\
\text { coupled data; } \\
\text { mesh structure }\end{array}$ & Algorithmic needs \\
\hline
\end{tabular}




\begin{tabular}{|c|c|c|c|}
\hline $\begin{array}{l}\text { Plasma } \\
\text { transport/ } \\
\text { turbulence }\end{array}$ & $\begin{array}{l}\text { Turbulent fluxes or } \\
\text { transport coeff; } \\
\text { axisymmetric } \\
\text { profiles }\end{array}$ & $\begin{array}{l}\text { Volumetric coupling; implicit; } \\
\text { for fluid, 2D fluxes/profiles for } \\
4 \text { or more moment variables - } \\
4 \times 50 \times 25 \text { minimum; if kinetic, } \\
\text { divide by number of fluid } \\
\text { moments/multiple by velocity } \\
\text { space ( } 50 \times 50) \text {; with fast } \\
\text { turbulence, may only need a } \\
\text { coupling frequency of } 1 /(\text { eddy } \\
\text { turn-over time) or transport } \\
\text { time scale; flux-surface mesh, } \\
\text { nonorthogonal for wall } \\
\text { structures }\end{array}$ & $\begin{array}{l}\text { Implicit desirable; } \\
\text { preconditioning/solving } \\
\text { large linear system }\end{array}$ \\
\hline $\begin{array}{l}\text { Fluid plasma/ } \\
\text { fluid neutral }\end{array}$ & $\begin{array}{l}\text { Plasma source/sink } \\
\text { due to neutrals; } \\
\text { neutral sources } \\
\text { (plasma fluxes to } \\
\text { surfaces); plasma } \\
\text { parameters; } \\
\text { plasma/neutral } \\
\text { collisional forces }\end{array}$ & $\begin{array}{l}\text { Volumetric; implicit; sizes } \\
\text { same as for plasma turbulence/ } \\
\text { transport except may have } 3^{\text {rd }} \\
\text { spatial dimension; frequency } \\
\text { depends on ionization/cx or } \\
\text { either ion/neut transport times; } \\
\text { plasma needs flux-surface } \\
\text { mesh, neutrals unrestricted }\end{array}$ & $\begin{array}{l}\text { Option of implicit } \\
\text { coupling }\end{array}$ \\
\hline $\begin{array}{l}\text { Fluid plasma / } \\
\text { kinetic neutral }\end{array}$ & $\begin{array}{l}\text { Plasma source/sink } \\
\text { due to neutrals; } \\
\text { neutral sources } \\
\text { (plasma fluxes to } \\
\text { surfaces); plasma } \\
\text { parameters; }\end{array}$ & $\begin{array}{l}\text { Volumetric; sizes same as for } \\
\text { plasma turb/transport except } \\
\text { may have } 3^{\text {rd }} \text { spatial } \\
\text { dimension; frequency as for } \\
\text { neutral fluid; plasma needs } \\
\text { flux-surface mesh, neutrals } \\
\text { unrestricted }\end{array}$ & $\begin{array}{l}\text { Reduce / eliminate Monte } \\
\text { Carlo noise in neutral data; } \\
\text { develop capability for } \\
\text { implicit coupling. Verify. } \\
\text { Approaches to simulating } \\
\text { neutral response to large } \\
\text { amplitude, intermittent } \\
\text { turbulent plasma. }\end{array}$ \\
\hline $\begin{array}{l}\text { Kinetic plasma } \\
\text { / kinetic neutral }\end{array}$ & $\begin{array}{l}\text { Kinetic specification } \\
\text { of neutral sources } \\
\text { (kinetic } \\
\text { characterization of } \\
\text { plasma fluxes to } \\
\text { surfaces); plasma \& } \\
\text { neutral fluid } \\
\text { parameters; later: } \\
\text { plasma \& neutral } \\
\text { distribution } \\
\text { functions }\end{array}$ & $\begin{array}{l}\text { With exchange of fluid } \\
\text { parameters, same as above. } \\
\text { With exchange of velocity } \\
\text { distribution functions (VDF), } \\
\text { scale by number of parameters } \\
\text { required to specify VDF in } \\
\text { each cell; frequency as for } \\
\text { neutral fluid; plasma needs } \\
\text { flux-surface mesh, neutrals } \\
\text { unrestricted }\end{array}$ & $\begin{array}{l}\text { Ensure conservation of } \\
\text { mass, momentum, and } \\
\text { energy in plasma-neutral } \\
\text { exchanges (not guaranteed } \\
\text { with moments exchange). } \\
\text { These techniques can be } \\
\text { used for nonlinear neutral } \\
\text { transport also. } \\
\text { Approaches to simulating } \\
\text { neutral response to large } \\
\text { amplitude, intermittent } \\
\text { turbulent plasma. Implicit } \\
\text { desirable }\end{array}$ \\
\hline
\end{tabular}




\begin{tabular}{|c|c|c|c|}
\hline $\begin{array}{c}\text { Photon } \\
\text { transport / } \\
\text { neutrals \& } \\
\text { plasma } \\
\text { (Adams / Scott } \\
\text { approach) } \\
\end{array}$ & $\begin{array}{l}\text { Optical depth; } \\
\text { modified effective } \\
\text { rates for ionization } \\
\& \text { recombination }\end{array}$ & $\begin{array}{l}\text { Volumetric times an order of } \\
\text { unity factor; frequency on } \\
\text { transport time scale; } \\
\text { unrestricted mesh }\end{array}$ & $\begin{array}{l}\text { (More thorough } \\
\text { verification required.) }\end{array}$ \\
\hline $\begin{array}{c}\text { Photon } \\
\text { transport / } \\
\text { neutrals \& } \\
\text { plasma } \\
\text { (coupled line } \\
\text { transport) }\end{array}$ & $\begin{array}{l}\text { Neutral \& plasma } \\
\text { parameters; rates for } \\
\text { line absorption and } \\
\text { radiation stimulated } \\
\text { ionization }\end{array}$ & $\begin{array}{l}\text { Volumetric times an order of } \\
\text { unity factor; frequency on } \\
\text { transport time scale; } \\
\text { unrestricted mesh }\end{array}$ & $\begin{array}{l}\text { (Any approximations } \\
\text { require adequate } \\
\text { verification) }\end{array}$ \\
\hline $\begin{array}{l}\text { Eroded \& re- } \\
\text { deposited } \\
\text { particles / } \\
\text { plasma \& } \\
\text { sheath }\end{array}$ & $\begin{array}{l}\text { Sputtered impurity } \\
\text { neutrals/ions; dust; } \\
\text { fluid or kinetic } \\
\text { plasma; sheath } \\
\text { model }\end{array}$ & $\begin{array}{l}\text { Surfacial: plasma flux to } \\
\text { surface/wall release model and } \\
\text { impurity flux to SOL plasma } \\
\text { model several ion radii from } \\
\text { surface. Volumetric: } \\
\text { hydrogenic plasma/neutrals } \\
\text { density, momentum, energy, } \\
\text { and potential as background to } \\
\text { evolve eroded particles/dust. } \\
\text { flux-surface plasma mesh or } \\
\text { interpolation to other mesh }\end{array}$ & $\begin{array}{l}\text { Noise reduction to } \\
\text { improve noise from using } \\
\text { particle data in continuum } \\
\text { plasma models }\end{array}$ \\
\hline $\begin{array}{c}\text { Hydrogenic \& } \\
\text { impurity fluxes } \\
\text { / material } \\
\text { evolution }\end{array}$ & $\begin{array}{l}\text { Incident particles; } \\
\text { surface/near surface } \\
\text { stoichiometry and } \\
\text { structure }\end{array}$ & $\begin{array}{l}\text { Surfacial with net particle flux } \\
\text { to surfaces; couples to material } \\
\text { code to describe } \\
\text { diffusion/trapping of plasma } \\
\text { species in the material \& } \\
\text { resulting material structure }\end{array}$ & \\
\hline $\begin{array}{l}\text { Plasma/neutral } \\
\text { s to the } \\
\text { pedestal/core }\end{array}$ & $\begin{array}{l}\text { Fluxes of particles, } \\
\text { momentum, and } \\
\text { energy; potential; } \\
\text { consistent physics } \\
\text { models, e.g., } \\
\text { transport } \\
\text { coefficients on each } \\
\text { side }\end{array}$ & $\begin{array}{l}\text { Surfacial, typically fluxes; } \\
\text { change in dimensionality ( } 2 \mathrm{D} \\
\text { edge, } 1 \mathrm{D} \text { core) introduces need } \\
\text { for averaging edge before } \\
\text { coupling; frequency on } \\
\text { transport (or tubulence if } \\
\text { coupled) time scale; consistent } \\
\text { B-field at coupling point; } \\
\text { overlap region useful }\end{array}$ & implicit desirable \\
\hline
\end{tabular}

There is also a question of where time-implicit coupling is important. The answer to this question depends on the shortest timescale in each component. In general, if an time-implicit component is explicitly coupled to a second component that has a fast timescale (whether 
that second component is implicit or explicit), the timestep required for the first component will likely degrade to that required for the explicit timescale of the second.

A few examples of present-day experiment in coupling boundary components follow in the next two paragraphs. The various processes in the SOL just described are generally tightly coupled, and some of the existing models include this coupling at some level. Foremost in this regard are the SOL/edge transport codes that include plasma, neutrals, and PMI models. The coupling between plasma and neutrals is treated either by using fluid neutrals that fit efficiently into the time-dependent algorithm for the plasma equations, or by using kinetic Monte Carlo neutral particles, which are more accurate but where efficient time-dependent coupling is an issue. Atomic-physics rate coefficients are used by both plasma and neutral models, and should be consistent. Transport of photons in the optically thick regime, especially Lyman- $\alpha$, can be done directly via a nonlinear Monte Carlo technique, as exemplified by the treatment in EIRENE [Reiter 2007]. In this case, the solution is obtained in an iterative manner; this approach, along with some associated approximations, should be verified. A simpler alternative approach is to incorporate radiation trapping effects directly into the effective hydrogen ionization and recombination rates via an additional optical depth parameter [Scott 2005], eliminating the need for explicit coupling to a radiation transport calculation. This technique was verified with a 1-D plasmaneutral transport tightly coupled to the radiation transport code, CRETIN [Adams 2005].

The coupling between transport and PMI codes is typically rudimentary in that only a single iteration is done and/or assumes a static wall [Brooks 2006]. A dynamic wall model has been coupled to a simple 1D plasma model [Pigarov 2008], and the FACETS SciDAC project is working toward coupling SOL/edge transport and dynamic wall codes as well as a core model [Cary 2009]. The coupling between transport codes and turbulence codes has been performed for isolated cases [Rognlien 2005], but important averaging issues and dynamic coupling are largely untouched. Furthermore, turbulence codes themselves do not include dynamic neutrals or impurities. Finally, plasma chemistry related to hydrocarbons in carbon walls has only been studied in isolated near-wall plasma/neutral models.

\section{b. Analysis of the requirements for the full workflow (task composition)}

The Boundary Science Driver shares with other science drivers the need to plan and execute simulations with a variety of components that can have very different computational requirements; e.g., in the coupling of turbulence and transport, the turbulence simulation will take much more CPU time and memory requirements than transport (unless the turbulence code performs both tasks). While all drivers will share the need for build systems, batch submission interfaces, and the like, we first mention some general capabilities of interest to the Boundary group. The framework should have the capability of efficiently testing individual components as well as various combinations of components. For the testing of individual components, a default static model of essential missing components should be available. For example, a plasma model should have access to a static neutral component and vice versa. It will also be important that the framework allow some level of usercontrolled steering for exploratory simulations. With respect to legacy codes, there is an issue if it is worthwhile for their elemental subcomponents to be exposed to the framework such that substitute subcomponents can be explored. This step requires a judgment of the value of the subcomponent, which is difficult to generalize. Finally, all science drivers will 
need ready access to high-quality visualization tools of simulation results and to experimental data accessible through the framework.

Framework task composition needs for the Boundary Science Driver that are at least quantitatively different from most of the other science drivers are as follows: As stressed earlier, the Boundary has a number of strongly interacting components within it own region that require strong coupling. Thus, while use of file-based coupling has some utility for special interactions, tight coupling will be much more important (see Table 4). If one or more of these components is omitted from a composed task, the substituted representation (say, for neutrals or wall recycling/sputtering) should be of sufficient quality that the approximated behavior is captured. For example, an edge transport simulation without any neutrals will far from experimental reality. Second, several processes are typically represented by data tables that use interpolation, such as ionization, recombination, sputtering, etc. Access to documented standardized tables as well as common variations is important. Third, the real space dimensionality of boundary is at least 2D and more generally 3D. Consequently, data visualization for simulation results and experimental results will be more demanding that for other regions.

\section{E. Validation requirements}

\section{a. Measurement requirements}

A crucial task of all FSP Science Drivers is the validation of both individual components and integrated models against measurements from experiments. In the Boundary Science area, special measurement challenges arise. The boundary plasma and surrounding surfaces are inherently 2-D or 3-D and typically feature steep spatial gradients, and the plasma is subject to highly intermittent and often strong turbulence, which dictates that PMI itself will be intermittent. The validation of integrated models will require advanced and in some cases new diagnostics. In particular, diagnostic techniques must extend beyond the realm plasma diagnosis to measurement of surrounding material surfaces. These surface diagnostics are very different from the largely spectroscopy techniques used for the plasma. In the table below we list the physics areas and measurements needed for validation, as well as important measurements that are not currently provided by the commonly available diagnostics.

Table 5. Critical physics and required measures for Boundary model validation

\begin{tabular}{|c|c|c|c|}
\hline Issue & Critical Physics & Measurements Needed & Important Gaps \\
\hline
\end{tabular}




\begin{tabular}{|c|c|c|c|}
\hline $\begin{array}{l}\text { Cross field } \\
\text { transport }\end{array}$ & $\begin{array}{l}\text { - Collisional and turbulent } \\
\text { transport of heat, particles } \\
\text { and momentum } \\
\text { - Effects of meso-scale short } \\
\text { wavelength MHD-like } \\
\text { modes } \\
\text { - Blobs (transport via } \\
\text { coherent structures) } \\
\text { - Role of magnetic } \\
\text { topology, magnetic shear, } \\
\text { x-point and wall/divertor } \\
\text { contact geometry }\end{array}$ & $\begin{array}{l}\text { - Time-averaged profiles of } \\
\text { ne, Te, Ti, perp. and } \\
\text { parallel flows } \\
\text { - Spatiotemporal resolved } \\
\text { fluctuation fields in near } \\
\text { and far SOL for ne, Te, } \phi \text {, } \\
\text { B and flow velocities } \\
\text { including amplitude, } \\
\text { relative phase, cross- } \\
\text { coherence } \\
\text { - Plasma turbulence mapped } \\
\text { along field lines to wall }\end{array}$ & $\begin{array}{l}\text { - Ti profiles } \\
\text { - Te, B fluctuations and } \\
\text { their correlation with } \\
\text { ne, } \phi \\
\text { - 2D coverage for } \\
\text { profiles and } \\
\text { fluctuations } \\
\text { - Synthetic diagnostics } \\
\text { (e.g. probe theory, } \\
\text { turbulence imaging) } \\
\text { - Simultaneous } \\
\text { fluctuation } \\
\text { measurements along a } \\
\text { field line }\end{array}$ \\
\hline $\begin{array}{l}\text { Heat and } \\
\text { particle } \\
\text { loads }\end{array}$ & $\begin{array}{l}\text { - Integration of perp. and } \\
\text { parallel transport, flows, } \\
\text { atomic and neutral physics } \\
\text { - Momentum transport - } \\
\text { plasma-neutral interactions } \\
\text { - Fueling, recycling and } \\
\text { retention } \\
\text { - Sheath heat transmission } \\
\text { physics } \\
\text { - Radiation transfer } \\
\text { - Transport in and through } \\
\text { private flux region } \\
\text { - SOL currents }\end{array}$ & $\begin{array}{l}\text { - Surface temperature } \\
\text { evolution } \\
\text { - Local plasma profiles, } \\
\text { plasma potential and } \\
\text { fluctuation near material } \\
\text { surfaces } \\
\text { - Neutral densities, transport } \\
\text { - In situ measurement of fuel } \\
\text { retention vs material, depth, } \\
\text { temperature } \\
\text { - Spectral measurements to } \\
\text { determine radiation opacity } \\
\text { - Tile currents } \\
\text { - Poloidal field }\end{array}$ & $\begin{array}{l}\text { - Local measurement of } \\
\text { recycling coefficients } \\
\text { - Atomic physics } \\
\text { - 2D coverage for } \\
\text { plasma profiles, } \\
\text { potential } \\
\text { - 3D coverage } \\
\text { - Transient } \\
\text { measurements } \\
\text { - Synthetic diagnostics } \\
\text { - Kinetic data in plasma } \\
\text { volume and at surfaces }\end{array}$ \\
\hline $\begin{array}{l}\text { Impurity } \\
\text { generation } \\
\text { and } \\
\text { transport }\end{array}$ & $\begin{array}{l}\text { - Impurity sources } \\
\text { - Collisional and turbulent } \\
\text { transport including flows } \\
\text { - Impurity sinks - } \\
\text { condensation, chemical } \\
\text { bonding, implantation, } \\
\text { co-deposition }\end{array}$ & $\begin{array}{l}\text { - Characterization of } \\
\text { impurity sources } \\
\text { - Impurity profiles and } \\
\text { transport (fluxes) } \\
\text { - SOL flows }\end{array}$ & $\begin{array}{l}\text { - 2D coverage for } \\
\text { sources } \\
\text { - 3D coverage for } \\
\text { impurity profiles } \\
\text { - Transient } \\
\text { measurements } \\
\text { - Hot walls }\end{array}$ \\
\hline
\end{tabular}




\begin{tabular}{|c|c|c|c|}
\hline $\begin{array}{l}\text { Evolution } \\
\text { of material } \\
\text { surfaces }\end{array}$ & $\begin{array}{l}\text { - Plasma heat and particle } \\
\text { sources } \\
\text { - Plasma material } \\
\text { interactions and evolution } \\
\text { of surface and sub-surface } \\
\text { structures } \\
\text { - Surface chemistry } \\
\text { - Effects of applied surface } \\
\text { coatings and cleaning } \\
\text { - Dust generation }\end{array}$ & $\begin{array}{l}\text { - Net erosion/deposition rates } \\
\text { - Offline measurements of } \\
\text { surface chemistry and } \\
\text { morphology (at all scales) } \\
\text { - In situ measurement of } \\
\text { surface stoichiometry, } \\
\text { morphology and dust }\end{array}$ & $\begin{array}{l}\text { - In situ measurements } \\
\text { - Steady state plasmas } \\
\text { - Hot walls }\end{array}$ \\
\hline $\begin{array}{l}\text { Interactions } \\
\text { with RF } \\
\text { fields }\end{array}$ & $\begin{array}{l}\text { - Creation of RF sheaths } \\
\text { - Impurity generation } \\
\text { - Ionization and heating of } \\
\text { SOL plasma } \\
\text { - Effects on launching } \\
\text { structures }\end{array}$ & $\begin{array}{l}\text { - RF sheath potentials } \\
\text { - Ion distribution functions } \\
\text { - Impurity generation } \\
\text { - Local Te, ne and ionization } \\
\text { rates in SOL } \\
\text { - Characterization of } \\
\text { launching structure surfaces }\end{array}$ & $\begin{array}{l}\text { - 2D, 3D coverage } \\
\text { - Plasma measurement in } \\
\text { presence of strong } \mathrm{RF} \\
\text { fields }\end{array}$ \\
\hline
\end{tabular}

\section{b. Plans for validation of critical physics associated with the science driver}

The level of measurements available in confinement devices necessarily impacts validation plans. It should be noted that highly resolved plasma and surface diagnostics are often readily available in linear plasma devices, and that to the extent possible, boundary science validation should exploit these devices to the fullest (e.g. PISCES, DIONISOS), With respect to the boundary area of confinement devices, the measurement challenges can be set into three broad categories which are described here:

1. Deployment of mature diagnostics with sufficient spatial extent and coverage. This topic is particularly important because it identifies a near-term (and relatively low risk) route by which boundary science validation is greatly improved. This includes

- scanning and fixed Langmuir probes with large poloidal coverage of SOL. This meets many of the requirements for 2-D static and fluctuating plasma fields and associated transport (density, temperature, flows); gas-puff imaging also provides important fluctuation measurements, though the impact of neutral profiles requires synthetic diagnostics that model neutral profiles

- Thomson scattering measurements of electron density and temperature usually extend into the SOL and profile key profile information, though multiple diagnostic signals typically need to be averaged owing to the intermittent nature of large fluctuations and the short duration of the Thomson data window

- scanning of fixed potential probes. These may be Langmuir probes or other special designs (emissive probe, ion sensitive probe)

- infrared thermography and thermocouples to provide high resolution energy /power balance to materials, especially the divertor plate regions 
- optical spectroscopy for impurity (gross) influx from surfaces, spatial profiles and impurity temperatures; validation of the long-range transport will require profiles of the impurity content, as well as plasma flow.

2. Allocation of experiments dedicated to boundary/PMI diagnosis. This category highlights the requirements for controlled, long-term exposure of plasma-facing surfaces in confinement devices, if ex-situ analysis of materials is required. Such experiments provide controlled and diagnosed exposure of surfaces in an integrated manner, however they require the dedicated, long-term use (multiple days typically due to short pulse lengths) of the confinement device. Examples include:

- exposure of material samples on retractable probes

- removal and analysis of plasma-facing components during vent access

- operationally "perturbing" experimental device operation: e.g. hot walls, oxygen baking

3. Development of new in-situ diagnostics. This approach includes either developing completely new diagnostic methods and/or the adaptation of existing ex-situ diagnostics to the confinement devices. Important diagnostic developments here are:

- main ion temperature in the SOL and divertor. The role of ions in heat exhaust is essentially completely unknown at this point; such measurements would be key in validating heat transport models in the $\mathrm{SOL} /$ divertor

- fast optical techniques to resolve geometric features of turbulence and plasma flows in high-temperature $\mathrm{H}$-mode

- plasma-facing surface diagnosis: erosion, stoichiometry, hydrogen isotopes

- velocity distributions of electrons and ions to examine kinetic effects

All of the options just mentioned can be considered with respect of a strategic plan. However, option 2) has been the status quo for much of PMI studies, and it is generally acknowledged that leads to very incomplete and ill-controlled measurement picture. In addition it is unlikely that confinement devices will switch large portions of their run time to boundary/PMI studies. Therefore it is likely that the optimal strategy will be

C. Short term program of increased deployment of standard diagnostics (2-3 years)

D. Proof of principle development of new diagnostics in 3-5 years. These can be performed either in off-line facilities or at small scale in confinement devices. Highest priority should be given to

- Ion temperature

- In-situ surface diagnosis

- Velocity distribution and flows

E. Deployment of new diagnostics in confinement devices (4-10 years)

\section{F. Connections to other work}

a. Relation to other work within the FSP

Development of an integrated plasma boundary model will depend on tools and codes produced by other groups within the FSP. In turn, other science application areas will 
require a boundary model, at some degree of complexity and fidelity, as an element in their own codes. The most direct connection is with the pedestal, which covers an overlapping spatial domain and a great deal of common physics. The physics of turbulence, cross-field transport and neutral transport are continuous across the separatrix with pedestal structures extending some small distance into the open field line region. Thus certain advanced components, for example for implementing gyrokinetic turbulence, Fokker-Planck collision operators, and kinetic neutral transport could be shared. We note, for example, experimental observations of an $\mathrm{E}_{\mathrm{r}}$ shear layer in the SOL of L-mode plasmas [LaBombard 2005] and the connection between SOL flows, equilibrium topology and the L-H threshold [Ritz 1990]. Initially, codes for each region will require simplified models to serve as boundary conditions for profiles and a calculation from the pedestal group of transient heat and particle loads from ELMs. The coupling likely requires consideration of fluctuation propagation, flows and other phenomena suggesting that ultimately, a common model for the boundary and pedestal plasmas will be required. As more sophisticated plasma-material models are developed, calculation of transient loading from disruptions will be needed as these can cause discontinuous change in the morphology and chemistry of the first wall. Wave-particle codes will need a plasma boundary model to account for the physics of parasitic losses and RF sheath generation. The two groups will need to work together for calculations of the resultant impurity production and local heat deposition. The boundary group will need to produce reduced models, perhaps at various levels of fidelity, for whole device modeling especially for impurity sources and fueling. Finally, production of the boundary model will also require the set of common FSP components, for example for 2D and 3D MHD equilibria and inclusion of the slow evolution of the equilibria, along with tools and infrastructure for software development support, user support, data management, software testing and release.

Table 6. Connections to other FSP activities

\begin{tabular}{|c|l|l|l|}
\hline Application Area & $\begin{array}{l}\text { Capabilities Needed } \\
\text { from Boundary }\end{array}$ & $\begin{array}{c}\text { Capabilities } \\
\text { Provided } \\
\text { to Boundary }\end{array}$ & $\begin{array}{l}\text { Capabilities Shared } \\
\text { with Boundary }\end{array}$ \\
\hline Pedestal & $\begin{array}{l}\text { Heat, particle, } \\
\text { momentum fluxes } \\
\text { Neutral and impurity } \\
\text { fluxes }\end{array}$ & $\begin{array}{l}\text { Heat, particle, } \\
\text { momentum fluxes }\end{array}$ & $\begin{array}{l}\text { Gyrokinetics } \\
\text { Fokker-Planck } \\
\text { Collisions } \\
\text { Kinetic neutral } \\
\text { transport }\end{array}$ \\
\hline Wave-Particles & $\begin{array}{l}\text { Plasma profiles } \\
\text { Fluctuation levels }\end{array}$ & $\begin{array}{l}\text { Local heat deposition } \\
\text { from fast particles and } \\
\text { RF }\end{array}$ & $\begin{array}{l}\text { Parasitic RF losses } \\
\text { and impurity sources }\end{array}$ \\
\hline Disruptions & & $\begin{array}{l}\text { Transient local heat } \\
\text { and particle loads }\end{array}$ & $\begin{array}{l}\text { Atomic and neutral } \\
\text { physics, radiation } \\
\text { transport }\end{array}$ \\
\hline Whole Device & $\begin{array}{l}\text { Reduced models for } \\
\text { boundary, especially } \\
\text { fueling, fuel retention } \\
\text { impurity sources }\end{array}$ & $\begin{array}{l}\text { Heat, particle, } \\
\text { momentum fluxes }\end{array}$ & \multicolumn{1}{|c|}{} \\
\hline
\end{tabular}




\section{b. Relation to work outside the FSP}

In its early stages, the plasma boundary model will depend on adaptation of existing physics components....

Further development of foundational theory will be required for the boundary model in several important areas...

1. Foundational theory

i. Kinetic theory applicable in boundary (perturbation size, scale separation, momentum equations, collision operators? ...)

ii. Sheath (and probe) theory including RF and surface roughness

iii. Models appropriate for multi-scale (space/time) materials modeling

2. Development or adaptation of existing components including those for

i. Fluid and kinetic turbulent transport

ii. 3D neutral transport

iii. Atomic physics packages

iv. Radiation transport models

v. Materials and PWI models 


\section{G. Schedule and resources}

The boundary region has a number of components of varying complexity that need to be coupled to provide a realistic model of this region. Consequently, there are a number of tasks that need to be carried out simultaneously, with lower-level models (e.g., fluid versus kinetic) providing the first coupled results that give way to more sophisticated models over time. The current coupled model can provide an evolving boundary module to be used for whole-device simulations at any time. An overview of the projected schedule of the work to be carried over a 15 year time period is provided by the following figure where the abscissa denotes years.

\section{Integrated Boundary Layer (SOL), Divertor, Plasma Wall Interactions Time Line}

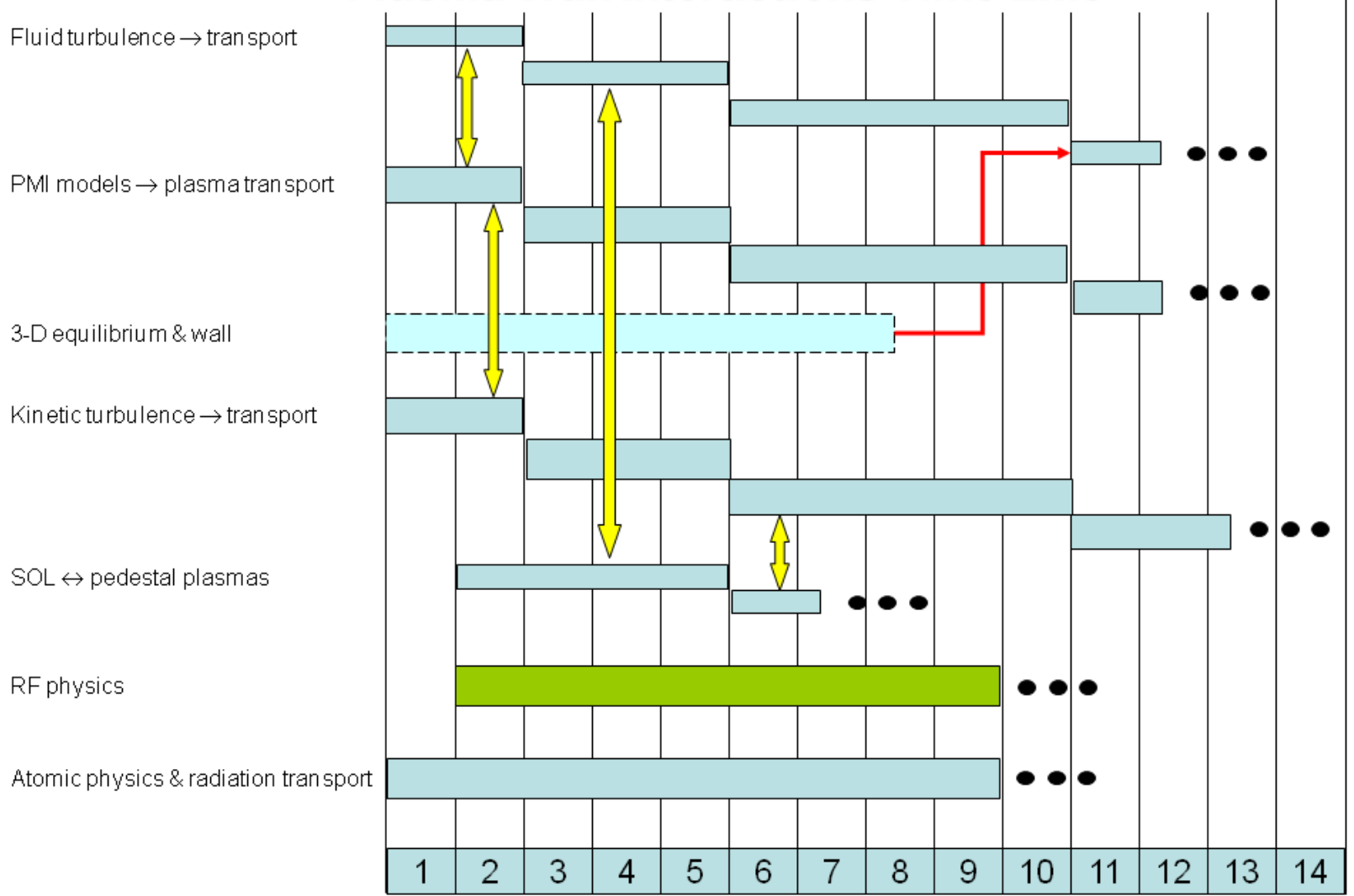

Fig. 2 Projected time line for development of coupled Boundary Science Driver components Each line in the chart corresponds to a separate Science Driver task; the height of the bars is intended to qualitatively reflect the relative manpower requirements associated with each task. The horizontal axis corresponds to calendar years. The dashed border of the "3-D equilibrium and wall" task indicates that this work is being undertaken by the base program outside of the FSP. The different color of the "RF physics" task indicates that it is part of a separate Science Driver. The yellow arrows indicate multiple exchanges of information \& capabilities; similar exchanges for RF and atomic physics are not shown for clarity. Red arrows denote one time or infrequent exchange of information between tasks. 
The elements of the boundary module are divided into tasks corresponding approximately to the rows in Fig. 1, though owing to staged development, some subtasks do not appear sequentially in the table. The schedule and resources for each is given below (PFTE=physicist FTE and $\mathrm{CFTE}=$ computational/math FTE):

\section{Task 1: Coupling fluid plasma turbulence, transport, and neutrals in the SOL}

- Years 1-2 [continuation of some of the development begun in FACETS]

- Couple SOL fluid plasma transport/turbulence; suitable micro-turbulence and/or transport codes exist; either iterative coupling between codes or long-time turbulence simulation with continuously evolving profiles: $1 \mathrm{PFTE} / \mathrm{yr}, 1 \mathrm{CFTE} / \mathrm{yr}$

- Couple neutral model, initially fluid; likely embedded in plasma fluid codes for coupling efficiency; verify with Monte Carlo: 0.25 PFTE/yr, 0.25 CFTE/yr

- Years 3-5

- Couple impurities and radiation transport models; impact of turbulence on impurity transport: 1.0 PFTE/yr, 1.0 CFTE/yr for 1.5 years.

- Extension of fluid turbulence to foot of pedestal region, begin to include long toroidal wavelength ELM modes: 0.5 PFTE/yr, 0.5 CFTE/yr.

- Couple dynamic kinetic neutral model; likely Monte Carlo: 0.5 PFTE/yr, 0.5 $\mathrm{CFTE} / \mathrm{yr}$ for 1 year

- Couple evolving MHD equilibrium to account for shifting separatrix: 0.5 PFTE/yr, 0.5 CFTE/yr for 1 year.

- Extend fluid neutral model to include additional species and equation for neutral temperature: 0.5 PFTE/yr, 0.5 CFTE/yr for 1 year.

- Improve coupling to kinetic Monte Carlo neutral model to reduce or eliminate statistical noise: $0.5 \mathrm{PFTE} / \mathrm{yr}, 1.0 \mathrm{CFTE} / \mathrm{yr}$ for 1 year

- Years 6-10

- 3D plasma transport; peaking factors of heat flux, PMI

- $\quad 3 \mathrm{D}$ magnetic fields

- $3 \mathrm{D}$ kinetic radiation transport

- Years 11-15

- $\quad$ TBD

Task 2: Coupling plasma-material interaction models with plasma transport

- Years 1-2

- Couple dynamic wall model for hydrogen wall uptake/recycling with dynamic 2D SOL plasma model 0.25 PFTE, 0.5 CFTE/yr

- Initiate full coupling between near-surface, particle-based sputter erosion/redeposition code for 2D impurities and SOL 2D fluid plasma model. Resolve possible particle-noise issues. 1.5 PFTE + 1.0 CFTE/yr 
- Provide the interface and a reduced material model that uses as input ELM and disruption characteristics, i.e., frequency, duration, and power, and can output the material response corresponding to, for example, a non-melting (acceptable) or melting (non-acceptable) condition. 1.0 PFTE + 1.0 CFTE/yr

- Improve data transfer between MD simulations and PMI models; 0.25 PFTE, 0.25 CFTE/yr

- Years 3-5

- Couple initial surface evolution model and near-surface plasma model; 1 PFTE/yr, 1 CFTE/yr

- Couple kinetic SOL to dynamic SOL models: 0.5 PFTE/y, 0.5 CFTE/yr

- Improve near-surface model coupling to MD model; 0.5 PFTE/y, 0.5 CFTE/yr

- Years 6-10

- Couple 3D SOL code to 3D near-surface and PMI codes: 1.0 PFTE/yr, 1.0 CFTE/yr

- 3D impurity transport, surface evolution, improved plasma/material interaction models 1.0 PFTE/yr, 1.0 CFTE/yr

- Years 11-15

- TBD

\section{Task 3: Couple kinetic plasma turbulence and transport in SOL}

- Years 1-2

- Couple (2D, 2v) kinetic SOL plasma with nonlinear Fokker-Planck collision model capable of full short-to-long mean-free path (leverage CPES and ESL): 2 PFTE/yr, 1 CFTE/yr

- Initial coupling (perhaps non-conservative) of kinetic plasma code to kinetic neutral model; demonstrate strong recycling and near steady-state $0.5 \mathrm{PFTE} / \mathrm{yr}$, $0.5 \mathrm{CFTE} / \mathrm{yr}$.

- Develop and extend kinetic Monte Carlo neutral transport component: 1 PFTE/yr, $0.5 \mathrm{CFTE} / \mathrm{yr}$.

- Years 3-5

- Couple kinetic (first electrostatic, then EM) turbulence to kinetic transport from foot of pedestal to wall: 2 PFTE/yr, $1 \mathrm{CFTE} / \mathrm{yr}$.

- Improved (conservative, more efficient) coupling of kinetic plasma code to kinetic neutral model: $1 \mathrm{PFTE} / \mathrm{yr}, 1 \mathrm{CFTE} / \mathrm{yr}$.

- Apply similar technique to nonlinear neutral transport problems in kinetic Monte Carlo code: 0.5 PFTE/yr, 0.5 CFTE/yr.

- Years 6-10

- Couple kinetic impurities to main ion transport; $1 \mathrm{PFTE} / \mathrm{yr}, 1 \mathrm{CFTE} / \mathrm{yr}$ 
- Extend kinetic domain well into pedestal; either couple to pedestal model or extend domain of single kinetic model

- Couple Kinetic ELM simulations; ejection, heat footprint

- Develop hybrid fluid-kinetic neutral transport component: 1 PFTE/yr, 1 CFTE/yr.

- Years 11-15

- TBD

\section{Task 4: Couple SOL and Pedestal plasmas}

- Years 2-5

- Begin extending fluid and kinetic transport well across separatrix (see Tasks 1 and 3)

- Years 6-10

- Years 11-15

Task 5: Couple RF antennas/physics with SOL and PMI models

- Years 2-5

- Years 5-10

- Years 10-15

\section{Task 6: Atomic physics models}

- Years 1-5

- Develop tractable characterization of high-Z atoms (already underway): 1 PFTE/yr.

- Calculate kinetic details for hydrogen molecular physics and incorporate into kinetic neutral transport model: 1 PFTE/yr.

- Years 6-10

- Identify and obtain data for molecular species pertinent to mixed material environment of ITER: 2.5 PFTE/yr, 0.5 CFTE/yr.

- Years 11-15

- Assemble improved data and simplified models for breakup of hydrocarbon molecules: 2 PFTE/yr, 0.5 CFTE/yr. 
Table 7. Summary of Schedule and Resources

$(\mathrm{P} / \mathrm{yr}=\mathrm{PFTE} / \mathrm{year}$ and C/yr $=\mathrm{CFTE} /$ year $)$

\begin{tabular}{|c|c|c|c|c|}
\hline & Year 1-2 & Year 3-5 & Year 6-10 & Year 11-15 \\
\hline \multirow{2}{*}{$\begin{array}{c}\text { Task } 1 \text { fluid } \\
\text { plasma/neutrals } \\
\text { transp/turb }\end{array}$} & $1.25 \mathrm{P} / \mathrm{yr} ; 1.25 \mathrm{C} / \mathrm{yr}$ & $2.5 \mathrm{P} / \mathrm{yr} ; 2.5 \mathrm{C} / \mathrm{yr}$ & $1.0 \mathrm{P} / \mathrm{yr} ; 1.0 \mathrm{C} / \mathrm{yr}$ & TBD \\
\hline & $\begin{array}{l}\text { Coupled SOL fluid } \\
\text { transport/turbulenc } \\
\text { e; coupled wall }\end{array}$ & $\begin{array}{l}\text { Couple impurities, } \\
\text { kinetic neutrals, } \\
\text { extend turb. }\end{array}$ & & \\
\hline $\begin{array}{c}\text { Task } 2 \text { PMI } \\
\text { models }\end{array}$ & $3 \mathrm{P} / \mathrm{yr} ; 2.75 \mathrm{C} / \mathrm{yr}$ & $2 \mathrm{P} / \mathrm{yr} ; 2 \mathrm{C} / \mathrm{yr}$ & $3.5 \mathrm{P} / \mathrm{yr} ; 2.5 \mathrm{C} / \mathrm{yr}$ & TBD \\
\hline \multirow{2}{*}{$\begin{array}{c}\text { Task } 3 \text { kinetic } \\
\text { plasma/neutrals } \\
\text { transp/turb. }\end{array}$} & $3.5 \mathrm{P} / \mathrm{yr} ; 2 \mathrm{C} / \mathrm{yr}$ & $3.5 \mathrm{P} / \mathrm{yr} ; 2.5 \mathrm{C} / \mathrm{yr}$ & $3 \mathrm{P} / \mathrm{yr} ; 2.5 \mathrm{C} / \mathrm{yr}$ & TBD \\
\hline & & & & \\
\hline \multirow{2}{*}{$\begin{array}{c}\text { Task } 6 \text { atomic/ } \\
\text { molecular } \\
\text { physics }\end{array}$} & $2 \mathrm{P} / \mathrm{yr}$ & $2 \mathrm{P} / \mathrm{yr} ; 0.5 \mathrm{C} / \mathrm{yr}$ & $2.5 \mathrm{P} / \mathrm{yr} ; 0.5 \mathrm{C} / \mathrm{yr}$ & $2 \mathrm{P} / \mathrm{yr} ; 0.5 \mathrm{C} / \mathrm{yr}$ \\
\hline & & & & \\
\hline $\begin{array}{l}\text { TOTAL } \\
\text { (FTE/yr) }\end{array}$ & 13.5 & $\mathbf{1 7 . 5}$ & 16.5 & \\
\hline & Ides & mary of $s$ & d resources & \\
\hline
\end{tabular}

\section{H. Milestones}

High-level goals and milestones are as follows:

\begin{tabular}{|l|c|}
\hline \multicolumn{1}{|c|}{ Milestone } & $\begin{array}{c}\text { Year from } \\
\text { inception }\end{array}$ \\
\hline Self-consistent SOL fluid plasma turbulence and transport (heat-flux width) & 2 \\
\hline $\begin{array}{l}\text { Dynamic coupling between PMI model and SOL plasma (integrated particle } \\
\text { inventory) }\end{array}$ & 2 \\
\hline Electrostatic kinetic turbulence and transport in SOL & 5 \\
\hline Surface evolution model & 5 \\
\hline $\begin{array}{l}\text { Extension of kinetic transport and turbulence into pedestal or coupling with pedestal } \\
\text { model }\end{array}$ & 10 \\
\hline Tritium transport and retention & 10 \\
\hline Electromagnetic kinetic turbulence and transport & 15 \\
\hline 3D kinetic transport - peaking factors & \\
\hline
\end{tabular}




\section{References}

[Adams 2004] M.L. Adams and H.A. Scott, Contrib. Plasma Phys. 44, 262 (2004).

[Baldwin 2009] M.J. Baldwin et al., J. Nucl. Mat. 390-391 (2009) 886.

[Batishchev 1997] O.V. Batishchev et al., Phys. Plasmas 4 (1997) 1672.

[Bonnin 2005] X. Bonnin et al., 32nd EPS Conf. on Plasma Phys., Tarragona, 27 June-1 July 2005 ECA 29C P-2.110

[Bonnin 2010] X. Bonnin and D. Coster, 19th International Conference on Plasma Surface Interactions, San Diego, May 24-28, 2010 (submitted to J. Nucl. Mater.).

[Borchardt 2001] M. Borchardt et al., J. Nucl. Mat. 290-293 (2001) 546.

[Brooks 2000] J.N. Brooks, D. Naujoks, Physics of Plasmas 6 (2000) 2565.

[Brooks 2002] J.N. Brooks, Fusion Engineering and Design 60 (2002) 515.

[Brooks 2009] J.N. Brooks, J.P. Allain, R.P. Doerner et al., Nucl, Fusion 49 (2009) 035007.

[Cary 2009] J.R. Cary et al., J. Phys . Conf. Series (2009)

[Chang 2005] C.S. Chang et al., Phys. Plasmas 11 (2004) 2649.

[Chankin 2009] A.V. Chankin et al., J. Nucl. Mat. 390-391 (2009) 319.

[Chankin 2006] A.V. Chankin et al., Plamsa Phys. Contr. Fusion 48 (2006) 839.

[Coster 2004] D.P. Coster et al., EFDA-JET-CP(04)07-08 (2004).

[Coster 2010] D.P. Coster, 19th Inter. Conf. Plasma Surface Interactions, May 24-28, San Diego (2010) Poster P3-08

[Dorr 2010] M.R. Dorr, R.H. Cohen, P. Colella et al. Proceedings of SciDAC 2010, July 11-15, Chattanooga, TN, 2010

[Dudson 2009] B. Dudson et al., Computer Physics Communications 180 (2009) 1467-1480.

[Eckstein 1991] W. Eckstein, Computer Simulations of Ion-Solid Interactions (New York, Springer).

[Exascale 2009] Report of the Workshop on Scientific Grand Challenges; Fusion Energy Sciences and the Role of Computing at the Extreme Scale: Panel 3-Plasma Material Interactions Science Challenges, March 18-20, 2009, Washington, DC, DOE, Office of Advanced Scientific Computing Research.

[Fantz 2001] U. Fantz et al., J. Nucl. Mater. 290-293, 367 (2001).

[Federici 2001] G. Federici et al., Nulc. Fusion 41 (2001) 1967.

[Feng 1999] Y. Feng, F. Sardei, F. and J. Kisslinger, J. Nucl. Mater. 266-269 (1999) 812.

[Feng 2006] Y. Feng et al., Nucl. Fusion 46 (2006) 807.

[Feng 2008] Y. Feng et al., Nucl. Fusion 48 (2008) 024012.

[Garcia 2003] O. Garcia et al., Plasma Phys. Contr. Fusion 45 (2003) 919.

[Greenland 2001] P.T. Greenland, Proc. R. Soc. Lond. A 457, 1821 (2001).

[Hassanein 2009] A. Hassanein, T. Sizyuk, I. Konkashbaev, J. Nucl. Materials 390-391 (2009) 777.

[Hassanein 2002] A. Hassanein, Fusion Engineering Design 60 (2002) 527.

[Hassanein 2002] A. Hassanein, I. Konkashbaev, J. Nucl. Materials 313-316.(2003) 664.

[Hillis 2001] D. L. Hillis et al., J. Nucl. Mater. 290-293 (2001) 418.

[Janev1987] R.K. Janev et al., Elementary Processes in Hydrogen-Helium Plasmas (Springer-Verlag, New York, 1987).

[Janev 2002] R.K. Janev and D. Reiter, Phys. Plasmas 9, 4071 (2002).

[Janev 2004] R.K. Janev and D. Reiter, Phys. Plasmas 11, 780 (2004). 
[Karney1998] C.F.F. Karney, D.P. Stotler and B.J. Braams, Contrib. Plasma Phys. 38, 319 (1998)

[Kim 2005] D.K. Kim and S.H. Hong, Phys. Plasmas 12 (2005) 062504.

[Kirnev 2005] G.S. Kirnev et al., J. Nucl. Mat. 337-339 (2005) 271.

[Kotov 2006] V. Kotov et al, Contrib. Plasma Phys. 46 (2006) 635.

[Krashenninikov 2010] private communication (2010)

[Krstic 1998] P.S. Krstic and D.R. Schultz, Atomic Plasma-Mater. Data Fus. 8, 1 (1998).

[Kukushkin 2005] A.S. Kukushkin et al., Nucl. Fusion 45, 608 (2005).

[LaBombard 2004] B. LaBombard et al, Nucl. Fusion 44 (2004) 1047.

[LaBombard 2005] B. LaBombard et al., Nucl. Fusion 45, 109 (2005).

[Lisgo 2005] S. Lisgo et al., J. Nucl. Mater. 337-339, 139 (2005).

[Lisgo2005a] S. Lisgo et al., J. Nucl. Mater. 337-339, 256 (2005).

[Loch 2006] S.D. Loch et al., At. Data and Nucl. Data Tables 92, 813 (2006).

[Loch 2009] S.D. Loch, C.P. Balance, M.S. Pindzola, and D.P. Stotler, Plasma Phys. Control. Fusion 51, 105006 (2009).

[Loarte 2001] A. Loarte, Plasma Phys. Contr. Fusion 43 (2001) R183.

[Matte 1988] J.P. Matte et al., Plasma Phys. Contr. Fusion 30 (1988) 1665.

[McTaggart 2004] N. McTaggart et al., Comp. Phys. Comm. 164 (2004) 318.

[Nordlund 2006] K. Nordlund, Phys. Scr. T124 (2006) 53.

[Park 2007] G.Y. Park, J. Cummings, C.S. Chang et al., J. Phys. Conf. Series 78, 012087 (2007).

[Pigarov 2005] A.Yu. Pigarov et al., Phys. Plasmas 12 (2005) 122508.

[Pigarov 2006] A.Yu. Pigarov et al., Contrib. Plasma Phys. 46 (2006) 604.

[Pigarov 2009] A.Yu. Pigarov et al., J. Nucl. Mat. 390-391 (2009) 192.

[Popovich 2010] P. Popovich et al. ...

[Post 1995] D.E. Post, J. Nucl. Mater. 220-222, 143 (1995).

[Reiter 2005] D. Reiter et al., Fus. Sci. Tech. 47 (2005) 172.

[Reiter 2007] D. Reiter et al., J. Nucl. Mater. 363-365, 649 (2007).

[Reiter 2009] D. Reiter, B. Kuppers, and R. K. Janev, Phys. Scr. T138, 014014 (2009).

[ReNew 2009] Report of the Research Needs Workshop (ReNeW) Bethesda, Maryland - June 8-12, 2009, DOE, Office of Fusion Energy Sciences

[Ritz 1990] C. Ritz et al., Phys. Rev. Lett. 65 (1990) 2543.

[Rognlien 1994] T.D. Rognlien et al., Contrib. Plasma Phys. 34 (1994) 392.

[Rognlien 2004] T.D. Rognlien et al., Contrib. Plasma Phys. 44 (2004) 188.

[Rognlien 2005] T.D. Rognlien et al., J. Nucl. Mat. 337-339 (2005) 327.

[Ryutov 1996] D. Ryutov, Contrib. Plasma Phys. 36 (1996) 207.

[Runov 2001] A.M. Runov et al., Phys. Plasma 8 (2001) 916.

[Russell 2009] D.A. Russell et al., Phys. Plasmas 16 (2009) 122304.

[Sawada 1995] K. Sawada and T. Fujimoto, J. Appl. Phys. 78, 2913 (1995).

[Schneider 1999] R. Schneider et al., J. Nucl. Mat. 266-269 (1999) 175.

[Schneider 2006] R. Schneider et al., Contrib. Plasma Phys. 46 (2006) 3.

[Scott 2004] H.A. Scott and M.L. Adams, Contrib. Plasma Phys. 44, 51 (2004).

[Sharafat 2009] S. Sharafat et al., J. Nucl. Mat. 390-391 (2009) 900. 
[Simonini 1994] R. Simonini et al., Contrib. Plasma. Phys. 34 (1994) 368.

[Smirnov 2010] R.D. Smirnov, 19th Inter. Conf. Plasma Surface Interactions, May 24-28, San Diego (2010); submitted to J. Nucl. Mater.

[Stangeby 1995] P.C. Stangeby, Plasma Phys. Controlled Fusion 37 (1995) 1031.

[Stangeby 2000] Peter C. Stangeby, The Plasma Boundary of Magnetic Fusion Devices (Institute of Physics Publishing, Philadelphia, 2000).

[Stotler 2000] D.P. Stotler et al., Contrib. Plasma Phys. 40 (2000) 221.

[Stotler 2001] D.P. Stotler et al., J. Nucl. Mat. 290-293 (2001) 967.

[Stotler 2005] D.P. Stotler and B. LaBombard, J. Nucl. Mater. 337-339, 510 (2005).

[Stotler 2007] D.P. Stotler, J. Boedo, B. LeBlanc, R.J. Maqueda, and S.J. Zweben, J. Nucl. Mater. $363-$ 365,686 (2007).

[Stotler 2010] D.P. Stotler et al.,19th Intern. Conf. Plasma Surface Interactions, San Diego, May 24-28, 2010 (submitted to J. Nucl. Mater.)

[Ueda 2009] Y. Ueda et al., J. Nucl. Mat. 390-391 (2009) ??.

[Umansky 2008] M.V. Umansky et al., Contrib. Plasma Physics 48 (2008) 27.

[Wichmeier 2009] M. Wichmeier et al., J. Nucl. Mat. 390-391 (2009) 250.

[Wichmeier 2010] M. Wichmeier, 19th Intern. Conf. Plasma Surface Interactions, May 24-28, San Diego (2010); J. Nucl. Mat., submitted, 2010.

[Whyte 2004] D.G. Whyte et al., Physica Scripta III (2004) 34.

[Xu 2005] X.Q. Xu et al., Nucl. Fusion 45 (2005) ???

[Xu 2007] X.Q. Xu et al., Nucl. Fusion 47 (2007) 809.

[Xu 2008] X.Q. Xu et al., Commun. Comput. Phys. 4 (2008) 949-979.

[Xu 2010] X.Q. Xu et al., Phys. Rev. Lett. 105 (2010)175005. 


\title{
J. Appendix: Answers to FSP management committee's follow-on questions
}

\author{
FSP Science Driver (Integrated Science Applications) Write-Ups \\ Comments, Questions and Requests for Additional Information
}

(Black from management committee and blue from Boundary group)

Below you will find a compilation of comments and questions from the FSP management team. Much of this is meant to clarify challenges and opportunities for Applied Math and Computer Science, which are important parts of the overall FSP effort. The first section applies to all of the write-ups (to a greater or lesser degree). This is followed by specific comments, targeted to each individual report.

We understand that completely addressing all of these issues could be quite time consuming in many cases. Our suggestion is to update the reports with the information that is readily available, leaving placeholders for more detail to be filled in over time.

\section{General Comments, Questions, Requests}

1. Where possible, specify both the discrete and continuous system of equations that each component solves.

This answer is a summary, and sometimes extension, of material that already exists in the main Science Driver document in order to address the question in a focused manner. Boundary region models must describe physical processes on open magnetic field lines that intersect material surfaces as well as a narrow region of adjoining closed field lines overlapping the core edge. A full description requires a number of components, and each area is discussed in turn with unique features highlighted:

\section{Plasma Transport}

Most often a set of fluid moment equations is solved for the plasma density, parallel momentum, and separate ion and electron temperatures. The geometry for tokamaks is $2 \mathrm{D}$ in the poloidal plane with symmetry assumed in the toroidal direction. These basic equations can also be used for 3D systems such as stellarators, though much less such work has been done for 3D in the US than for 2D. These equations are partial differential equations of the convection-diffusion-reaction type with most terms in a divergence form

$$
\partial \mathrm{M}_{\mathrm{i}} / \partial \mathrm{t}+\nabla_{\mathrm{r}} \bullet\left(\mathrm{M}_{\mathrm{i}} \mathbf{v}\right)+\sum \mathrm{g}\left(\mathrm{M}_{\mathrm{i}}, \mathrm{M}_{\mathrm{j}}\right)=\sum \mathrm{h}\left(\mathrm{M}_{\mathrm{i}}, \mathrm{M}_{\mathrm{j}}, \mathrm{M}_{\mathrm{n}}\right)
$$

where $\mathrm{M}_{\mathrm{i}}$ is a plasma moment depending only on the real space coordinates $\mathbf{r}, \mathbf{v}$ a velocity from convection and diffusion, $\mathrm{g}$ a possible additional coupling between plasma moments, and $\mathrm{h}$ a coupling function for interactions with neutral moments, $M_{n}$. The electrostatic potential is determined from the plasma current continuity equation. A 2D finite-volume numerical method is typically used to solve these equations, though finite elements have also been used. In 3D, finitevolume, finite-difference, and test-particle methods have been developed, mostly in the EU.

The kinetic transport models compute the velocity distribution, f, by adding two velocity dimensions with some form of gyro-averaging over the third velocity component, giving rise to a gyro-kinetic equation; an equation that includes only the lowest order gyro-radius effects related to cross-field particle drifts is called the drift-kinetic model. The spatial features of the equations are basically the same as for the moment equation.

$$
\partial \mathrm{f}_{\mathrm{i}} / \partial \mathrm{t}+\nabla_{\mathrm{r}} \bullet\left(\mathrm{f}_{\mathrm{i}} \mathbf{v}\right)+\nabla_{\mathrm{v}} \bullet\left(\mathrm{f}_{\mathrm{i}} \mathbf{a}\right)+\sum \mathrm{g}\left(\mathrm{f}_{\mathrm{i}}, \mathrm{f}_{\mathrm{j}}\right) \ldots=\sum \mathrm{c}\left(\mathrm{f}_{\mathrm{i}}, \mathrm{f}_{\mathrm{j}}\right)+\sum \mathrm{h}\left(\mathrm{f}_{\mathrm{i}}, \mathrm{f}_{\mathrm{j}}, \mathrm{f}_{\mathrm{n}}\right),
$$


where $f_{i}$ is a $4 D$ particle distribution depending on real space and velocity spaces coordinates $(\mathbf{r}, \mathbf{v})$, $\mathbf{a}$ is acceleration from a force, $\mathrm{g}$ a possible additional coupling between components, $\mathrm{c}$ is the Coulomb collision operator (a 2D second-order convection-diffusion operator in velocity space), and $h$ a coupling function for interactions with neutral-particle distribution, $f_{n}$. The electrostatic potential is obtained from either the long-wavelength limit of the gyrokinetic Poisson equation or the current continuity equation. Two numerical approaches have been used to solve the kinetic equation, one is the particle-in-cell method where $\mathrm{f}_{\mathrm{i}}$ is represented by an ensemble of particles, and the other is a continuum method where $\mathrm{f}_{\mathrm{i}}$ is discretized on a 4D mesh. Some Monte Carlo test-ion models are also in use that tracing impurity trajectories in main plasma (hydrogenic ions + electrons) profiles and electrostatic fields given by some other calculation; these typical do not include magnetic cross-field drifts, but could.

Unique features for the Boundary region plasma transport equations are as follows:

- Plasma variation along the magnetic field is explicitly solved for bringing in fast time scales associated with parallel (along the magnetic field) streaming and diffusion; thus must resolve highly anisotropic parallel and perpendicular transport.

- Resolving anisotropic transport gives rise to anisotropic meshes that also must adjust to long parallel scale-lengths at the outer midplane to short parallel scale-lengths near the divertor plates. Consequently, mesh spacing changes substantially over the simulation domain.

- Inclusion of classical plasma drifts across the magnetic field $(\nabla B$ and B-curvature, plus ExB) add large convective terms whose flux-surface average is close to zero on closed Bfield lines. These drifts are central to the kinetic description but are less regularly used in the fluid approach.

- For the collision operator in the kinetic equation method, a set of Rosenbluth potentials must be determined. The simplest method is to use those for a Maxwellian distribution, but in the edge region, the anticipated departure from a Maxwellian requires a more detailed method. In general, these potentials are the solution to two coupled second-order Poisson-like equations in velocity space with coefficients involving integrals of $\mathrm{f}$.

- Source and sink terms associated with ionization of neutrals and recombination of plasma can be strong and are highly nonlinear; ion charge-exchange with neutrals can be large, coupling ion and neutral equations.

- While magnetic flux surfaces are usually used for one of the two spatial coordinates, material surface boundaries generally do not conform to flux surfaces; thus, non-orthogonal, body-fitting meshes should be used at these material interfaces.

- The number of species that need to be followed in the Boundary can be large owing to the fact that impurities are both numerous and likely not is coronal equilibrium, requiring each charge-state to be evolved independently (with some progress toward "bundling" adjacent charge-states).

- For 3D systems, dealing with strong magnetic shear in the edge/boundary region is challenging and generally requires some type of regular remapping of the solution to slight different coordinates at specified toroidal positions to maintain the accuracy of the strong parallel transport and ensure it does not pollute the cross-field transport.

Plasma Instabilities and Turbulence

The basic equations already described can also be used for plasma turbulence by allowing plasma/field variations in the toroidal direction. Thus, fluid turbulence becomes 3D and (gyro) kinetic turbulence 5D. For the EM field equations, in addition to electrostatic potential via either Poisson or current continuity equations, the parallel magnetic vector potential is sometimes included from a reduced form of Maxwell's equations. As for transport, there are a number of special issues that distinguish the Boundary region turbulence from that in the core. The multi- 
species issues mentioned in the transport section apply, but are not repeated here. Special issues for Boundary plasma turbulence are:

- Fluctuation amplitudes can be large, i.e., of order unity in the SOL, which requires careful justification of the underlying equations in an implementable form.

- Turbulence can be intermittent, which together with the large amplitude, raises a serious question of applicability of using long-time averages with couple turbulence and transport.

- There is often no substantial separation of turbulence scales (e.g., eddy size) and axisymmetric radial gradient scale-lengths. Furthermore, axisymmetric equilibrium quantities such as density, temperature, and electrostatic potential can vary substantially along magnetic field lines, unlike in the core where they are nearly constant in this direction.

- Magnetic shear, especially near the magnetic separatrix in divertor geometry makes accurate numerical differencing difficult when resolving the inherent parallel/perpendicular transport anisotropy.

- For kinetic simulations, it is likely that the $\delta$ technique, which assumes the distribution function is only weakly perturbed from a Maxwellian $\left(\delta \mathrm{f} / \mathrm{f}_{\mathrm{M}}<<1\right)$ as widely used for the core plasma, is inadequate for Boundary turbulence.

Neutral, photon, and dust transport

The transport of neutrals and photons is grouped together because both are zero-charge particles unaffected by electromagnetic fields. Most fusion code development has been for neutrals and can use either fluid or moment description or a kinetic description. Both approaches included 2D and 3D capabilities with the dimensionality typically chosen to be the same as the dimensionality of the plasma model. To date, the workhorse neutral kinetic models are Monte Carlo codes. Likewise, Monte Carlo is the present method for describing the trajectories of charged dust particles and their ablation by the plasma. A key benefit of the Monte Carlo approach (at least for linear problems) is that the individual particle trajectories are independent, making the algorithm easy to run in parallel. Special issues for Boundary modeling are:

- The outer wall boundary that emits neutrals can be complex, but must be included to give an accurate model.

- For fluid models, while convenient, they require limiting transport coefficients in long meanfree path regimes; these models need to be calibrated by kinetic codes and the generality of such calibrations is uncertain

- Monte Carlo codes are inefficient in representing regions of high plasma density (e.g., near divertor plates) because the large charge-exchange collision frequency requires small timesteps for a region that could be represented by a continuum diffusion equation. A hybrid kinetic/fluid model would be most efficient.

- A significant drawback of Monte Carlo methods is the statistical noise introduced into the resulting integrals of the neutral (or photon or dust) distribution function that are used in coupling to plasma codes. Methods of reducing or eliminating that noise would simplify inclusion of kinetic Monte Carlo codes in a general code-coupling framework.

- For high neutral densities (e.g., near divertor surfaces) can yield strong neutral-neutral collision, yielding a nonlinear problem to solve, which requires extension of the basic linear Monte Carlo approach; presently an iterative fluid representation of the nonlinear terms is used. The neutral-neutral collision frequencies used in this method are chosen so that the exchanges conserve momentum and energy, and so that the resulting transport matches experimentally measured diffusivity and viscosity. However, the thermal conductivity of the neutral fluid is overestimated by $50 \%$ in the process. A more accurate treatment may be required to accurately simulate such conditions in future devices.

- Regions of high neutral density can be optically thick to some hydrogen line radiation. In the approach most widely used at present, the neutral-photon coupling is handled in a 
manner analogous to that of the neutral-neutral nonlinearity. More efficient and more accurate coupling techniques would be useful here as well.

Plasma-material interactions

The interaction of the plasma and neutrals with material surfaces itself involves a number of processes and can be further divided into (1) release of particles at the surface into the plasma (recycling, sputtering) including their eventual return to the surface (re-deposition) and (2) the heating of the material and migration of particles in the solid (retention and outgassing). For (1), generally Monte Carlo neutral/ion models are used with full gyromotion near the surface, though multi-species plasma transport models already discussed can approximate such transport if gyrosheath effects don't dominate for escaping particles. For transport within the material, at least three types of models are used: or the much more detailed molecular dynamics (MD) model that includes the interactions with individual lattice ions, Kinetic Monte Carlo that traces particles and defects (?), and continuum fluid models of the same. Special issues for Boundary modeling are:

- How to bridge the gap between the extremely short MD simulation timescale (psec) and that of the evolution of the plasma.

- Fuller development of surface evolution models or collaborating with the existing material processing community tools.

2. What is the range of spatial and temporal scales for each component?

Already addressed in the Boundary Science Driver writeup - see Tables 1-3.

3. Will any components generate sizable datasets that would benefit from inline data analysis and/or reduction?

Turbulence plasma simulations (3D fluid or 5D kinetic) will produce very large datasets, as in the core region. Improved data analysis would be helpful, but at present, the use of inline analysis is not thought through; something to consider.

4. What sizes and dimensionality of data are present in data transfers (both between components and for $\mathrm{I} / \mathrm{O})$ ?

Already addressed in the Boundary Science Driver writeup - see Table 4.

5. Does your ISA require the incorporation of knowledge discovery methods and tools into the framework? (A clarification: by "discovering methods," this question is primarily asking about the potential utility of data mining for large, multi-dimensional data sets)

A description of the Boundary required coupling a number of models, many be "reduced" in some sense from the most complete model. Here such discovery methods could help in understanding the interaction of these components. There are also more fundamental models, especially for turbulence simulations (fluid or kinetic in the appropriate parameter regime), that could potentially benefit from "data mining." However, there is much to do to ensure that the basic models are working properly (verification) and care must be taken to not prematurely embark on such mining exercises.

6. What is needed in terms of verification tools and methodology?

The Boundary region is characterized by complex geometry and coupling of different physical processes. Consequently, while the basic components can and should be verified in simple geometry with some known analytic solutions, there is a very important need to extend verification to include manufactured solutions and code-code comparisons. The latter area may be one where international collaborations would be fruitful. 
7. What significant vis tools are needed

Visualization of edge and divertor simulations are complicated by the disparate length scales (microns or smaller for materials, millimeters for neutral species and sharp plasma gradients, meters for variations along field lines), the inherent 2D (and eventually 3D) nature of the problems, and the large range of the variables.

8. In addition to the detailed breakdowns provided by many groups, a more concise summary of resource requirements would be helpful.

Two types of resources are required - hardware and personnel. The upper dimensionality of physics codes to be solved and the number of such codes roughly indicate the hardware requirements. For the SOL transport, time-dependent 4D kinetic codes on meshes of $\sim 50 \times 50 \times 50 \times 50$ are needed with multiple ions species to include impurities ( $\sim 10$ or more) plus electrons. For SOL turbulence, 5D kinetic codes add a $5^{\text {th }}$ dimension and finer time resolution likely more demanding than core codes because of non-Maxwellian features. Particle codes trade two velocity dimensions for number of particles in a real-space cell, but for computation of the Coulomb collision operator still requires a velocity-space mesh or series expansion.

Near surface and material codes have similar demands and though turbulence is not included, the enormous range of timescales mean multiple codes must be ultimately coupled.

Personnel requirements are still being developed.

\section{Boundary: Specific Comments, Questions, Requests}

1. Why have algorithms for fluid-kinetic neutral transport not been implemented? Are there practical barriers that require further algorithmic development?

There presently exists some aspect of fluid-kinetic models in the Monte Carlo neutral codes DEGAS 2 and EIRENE, but it is limited to the description of neutral-neutral collisions and not neutral-ion collisions. There has been some success for such techniques for neutral-only systems [e.g., L. Pareschi and R.E. Caflisch, "An implicit Monte Carlo method for rarefied gas dynamics", J. Comput. Phys. 154 (1999) 90; and V.I. Kolobov, R.R. Arslanbekov, V.V. Aristov, A.A. Frolova, and S.A. Zabelok, "Unified solver for rarefied and continuum flows with adaptive mesh and algorithm refinement," J. Comput. Phys. 223 (2007) 589]. Developing related methods for neutral-plasma systems has been proposed to DOE in the past, but not funded as far as we are aware; thus progress is to a significant degree limited by funding.

It should also be mentioned that while appealing on the surface, such methods have been developed for plasma models with mixed results as the "devil is in the details" in terms a making an efficient, accurate, and robust scheme. Outside of of kinetic models, there doesn't seem to be large-scale use of such methods for plasmas. Nonetheless, developing such a hybrid neutral model for plasmas would be very useful, though the amount of work involved should be carefully analyzed.

2. Does "neutral response to large amplitude, intermittent turbulent plasma" refer to "blobs"? What is the numerical issue here?

Yes, this is a reference to plasma "blobs," which is jargon for intermittent, large amplitude plasma filaments that accelerate radially to the surrounding wall. These plasma structures are observed experimentally and in turbulence codes (e.g., BOUT and SOLT). The numerical issues are (1) strong spatial nonlinearity in both the plasma and the neutral response (large amplitude variations) and (2) rapid time response as the "blob" is rapidly moving. Implementation of a dynamic neutral model, either fluid or Monte Carlo, in the turbulence codes is needed. 
3. Are there known algorithms for the implicit coupling of fluid plasma and Monte Carlo neutral models?

Yes, some implicit methods have been used for coupling EIRENE/SOLPS (B2). Here, a limited amount of implicitness in its coupling (the source terms are linearized). A more aggressive approach to treating charge exchange implicitly based on the analogous technique developed for radiation transport [Fleck and Cummings (1971), Fleck and Canfield (1984), Larsen and Mercier (1987)] was contemplated, but we don't believe it has been implemented.

4. In what sense is conservation of mass, momentum, and energy in kinetic plasma-neutral exchanges an issue?

There is some issue here, though there are methods available to ensure such conservation. Because of very strong particle recycling, particle conservation can be demanding. For the older EIRENE/SOLPS version (V4) used for ITER modeling by the ITER Organization, Kukushkin has implemented an additional particle conservation technique that he reports as adequate, though it is not clear that it conserves momentum and energy as well.

In the approach employed in XGC0 - DEGAS 2 (in which the codes exchange fluid moments of the plasma and neutral distribution functions), conservation of mass can be ensured, but conservation of momentum and energy cannot. Obtaining conservation requires either the exchange of more detailed information about the distribution functions or explicit binary collisions. The problem with the latter is the dramatic increase in computational resources required.

5. What is the role of kinetic versus fluid models in the scrape-off layer?

At a high level, kinetic edge codes have two added velocity dimensions making them much more computationally demanding and less mature than fluid codes. Thus, one can envision using fluid codes to more efficiently scope out parameter space and allow understanding of long timescale processes that arise from strong particle recycling and temporally varying wall conditions. Plasma kinetic codes can then be used to give more detailed results and to study effects missing from the fluid models, specifically large ion drift orbits at low collisionality and non-Maxwellian distributions for ions and electrons. For neutral species, kinetic behavior can arise from recycling at the wall, un-collided dissociation products, and charge exchange with non-Maxwellian ions. As they mature, the kinetic codes can help parameterize simpler reduced models for use in the faster fluid codes. Also, fluid models can provide benchmark targets for kinetic codes in the strongly collisional regime, as can arise in the Alcator C-Mod tokamak, where both types of models should give the same answer.

6. Is the noise issue for reducing statistical noise purely an issue of noise in the solution or also an issue of noise in coupling quantities to deterministic models, e.g. fluxes between a particle and fluid representation at an interface?

Yes, interface noise when coupling between one region having a statistical (e.g. discrete particle) model and a second having a continuum model would likely present the same efficient algorithmic issue as coupling between two species components having different descriptions (e.g., a fluid plasma model and Monte Carlo neutrals in the boundary). This issue has arisen in coupling the implicit plasma fluid continuum code UEDGE and the DEGAS 2 neutral Monte Carlo code [Rensink; Stotler] owing to the lack of a preconditioning Jacobian for the plasma-neutrals interactions.

7. What are the main challenges in the advancement of algorithms for dust models?

Numerical advances needed are parallelization of dust trajectory codes (e.g., DUSTT), appropriately averaged transport (similar to "blobs") of dust to be coupled to plasma transport 
codes, coupling to dust generation models, and extension of models to the $3 \mathrm{D}$ wall structure. Physics improvements needed include improved dust generation models, vapor shielding, internal dynamics, and dust-wall collisions.

8. What are the issues that you would like to resolve for plasma transport/turbulence coupling that require new preconditioners? How large are the anticipated linear systems?

Because boundary plasma modeling involves solving for fast parallel dynamics even for the 2D transport and involves slowly evolving recycling and wall physics, there is an especially large range of timescales involved in modeling this region. For 2D transport, it has been shown that preconditioning the system with a finite-difference Jacobian can be very efficient for obtaining a sequence of steady-state solutions. For 3D fluid turbulence, only very simple preconditioners have been tried to step of fast Alfven-modes that have a weak effect on the resistive-drift instabilities being studied; however, the effectiveness of these simple preconditioners has been modest. The goal is to find a minimal physics-based preconditioner that would be effective in stepping over the Alfven-mode time-scale. On the other hand, a full-blown finite-difference Jacobian for such 3D systems would be quite large to invert - on the order of $10^{7}$ elements, and even that would require modification to present $3 \mathrm{D}$ algorithms to solve for the electrostatic and parallel vector potentials as primary dynamical variables instead of the present method of solving for them through secondary global constraint equations.

9. What are the "important averaging issues and dynamic coupling" between transport and turbulence codes that are largely "untouched"?

Boundary turbulence is often characterized by large amplitude, intermittent fluctuations ("blobs"). Such transport events are not well represented as a small-amplitude diffusion process where the time-average of the turbulent fluxes gives a reliable description of the transport process. For large amplitude, intermittent fluctuations, each event can substantially alter the background plasma momentarily, followed by a long quiescent period. A proper average description usable by transport codes could be approached via probability distribution models, and this is the area referred to as largely "untouched" in the write-up.

10. What level of fidelity is actually required of a radiation-transport model? Do existing radiation transport codes in other application areas provide this or is a new specialized solver required?

The plasma in MFE devices is typically optically thin to most radiation lines with the exception of hydrogen, primarily for the Lyman- $\alpha$ line. Here two approaches have been used: one is to include photon transport in Monte Carlo codes that also track neutrals as done in EIRENE [Reiter 2007, Kotov 2006]], and the second is to parameterize a reduced "escape factor" model using the existing radiation transport code CRETIN [Scott and Adams], which may be adequate for highopacity tokamak divertors (such as ITER and burning plasma devices). It will need to be demonstrated that these reduced models adequately reproduce the more detailed model. In terms of impact, the evidence so far is that such effects are not dominant in determining the overall plasma parameters, and especially the peak heat flux, but limited testing has been done. Coupling such radiation transport codes to edge transport codes has many of the same issues at for neutral transport, and both could be considered together.

11. Is the further development of "Foundational theory" purely a theoretical physics pursuit, or are there opportunities for applied mathematics contributions? Are these all envisioned to occur outside of FSP?

One of the ongoing issues for the Boundary region is developing an implementable gyrokinetic system of equations applicable to the steep radial gradients and large amplitude fluctuations. 
Progress has been made, but for very large amplitude fluctuations, inclusion of all three velocitydimensions (i.e., not gyro-averaging) in plasma simulation models may be necessary (this is more a numerical issue more than a foundational theory issue). A second area involves developing/adapting probability distribution models for transport generated by large, intermittent events ("blobs").

12. Is HEIGHTS adequate, or is further model and numerical development needed? How much molecular dynamics modeling of materials is really necessary for accurate modeling of the plasma? Do the efforts at LLNL and LANL provide enough information to address this?

The HEIGHTS code package is quite comprehensive and may be adequate for detailed computations of many plasma transient interactions with surfaces. However, there are many complicated processes on the surface and in the nearby bulk materials that have not been thoroughly validated, especially in the tokamak setting. Thus, due to the very complexity of both HEIGHTS and processes in this region, a subset of HEIGHTS' or similar models is recommended for initial ( years 1-3) use in FSP, followed by a fuller implementation later.

More generally, material properties can impact fusion devices in two ways, one is for performance of the core plasma confinement for producing fusion neutrals, and the second is the lifetime and activation of the materials themselves. It is well established that wall conditioning by various means can have a strong effect on core performance; indeed, virtually all present-day tokamaks utilize some form of wall conditioning. But once conditioned, tokamaks with quite different material walls (e.g., carbon or molybdenum) can operate in the same regimes. Yet, we do not really know which characteristics of the material state are most directly responsible for the sensitivity of plasma performance to "wall conditions". Due to the complexity of plasma-material interactions and the difficulty in diagnosing them, in the long run may have little choice but to address this question, and the others that must be answered in the design of materials for burning plasma devices, by assembling a hierarchy of models, the starting point of which would be a molecular dynamics (MD) model. The goal here is to use the knowledge to yield higher-level characterizations coupled to plasma models suitable for more efficient, rapid simulations.

In the first several years, MD modeling is not essential for initial plasma/surface analysis implementation. Subsequently, MD is still not needed for numerous cases, but can be useful for certain material/plasma-regime situations. Specifically, for single-material, non-carbon sputtering computations and carbon physical-sputtering-only computations, binary collision codes are adequate (including near sputtering threshold energy cases where collective effect add-on models can be used in the binary collision codes).

Chemical sputtering of carbon is important for near-surface plasma temperatures of $\sim 5 \mathrm{eV}$ and lower. (Chemical sputtering for higher temperatures tends to be much less important-it occurs, but the sputtered hydrocarbon re-deposition fraction approaches $100 \%$ ). Analysis of the transport of chemically sputtered carbon has made major use of the results of MD codes, and will likely continue to do so. However, real-time MD use for carbon analysis, as opposed to a look up table type approach, does not appear to be critically needed in an FSP setting. Also, it is questionable whether an FSP project should even spend the resources on developing a detailed capability for carbon chemical sputtering computations, inasmuch as carbon will not be used in the D-T phase of ITER or subsequent machines (due to tritium co-deposition and other concerns). (Note that physical sputtering computations for carbon can be readily included in FSP-along with Be, W, etc. single materials).

MD is being used for mixed-material (e.g. Be/W, C/Li) surface response calculations, and this is an important research area. Initially, however, kinetic binary collision codes (with possible validation with selected MD analysis) can be used in FSP for plasma/surface analysis of mixed materials. It would be desirable for MD codes, if feasible, to be incorporated into FSP at a later date. This would possibly involve associated quantum calculations for the mixed-material 
potential. Real time coupling of MD codes, with e.g., the REDEP/WBC code package would be desirable.

It should be noted that in addition to LLNL and LANL, there are robust MD efforts at ORNL, and other US and international institutions. Per the above comment, a detailed assessment of MD capability is not required in the initial FSP phase, but would be needed later.

13. Discussion of the physics components confusing. Some components are touted as state-of-the art in one place yet cited as not ready in another e.g. HEIGHTS, REDEP/WBC. Better identification of the physics and component gaps would be helpful

The REDEP/WBC code package is comprehensive, being single-particle Monte Carlo, (3D, $3 \mathrm{~V})$, fully kinetic, with all relevant processes included or includable. Substantial numerical work, however, would be required to integrate this package with plasma edge/SOL and material response codes, e.g., in terms of grid coordination, time and space scale compatibility; this is true of course of much of the FSP inputs. Also, model/sub-codes for some key processes need considerable work, prior to inclusion in REDEP/WBC, such as for tungsten tendril and helium bubble formation in the plasma-interaction zone $(\sim 100 \mathrm{~nm})$ under $\mathrm{D}, \mathrm{T}$, He bombardment, and mixedmaterial formation/evolution and response.

14. Is there an opportunity to take advantage of the clear difference between parallel and perpendicular transport in the open field line to develop reduced models, or simplify the problem?

The large difference between parallel and perpendicular transport results in profiles that long and thin such that the parallel and perpendicular fluxes are of the same order. Thus, there is no general reduction available (though 1D models of parallel transport for some assumed width can be useful). An issue that does arise here is that the neutrals have isotropic transport owing to charge-exchange collisions with ions, but the same collisions tends to also make the neutral profile somewhat long and thin in the divertor legs. The plasma is usually represented on an anisotropic mesh to accommodate the anisotropic transport, and if fluid neutrals are solved on the same mesh with isotropic transport, there could be some numerical issues associated with the neutral equations in a parallel domain-decomposition setting.

15. How to model the connection between the scrape-off-layer (SOL) and the divertor, two regions with very different parameters

The plasma collisionality in the divertor region is usually substantially higher than at the midplane of the SOL, so splitting the regions has some rationale. However, there is a continuous range of collisionality, so it is not clear where to split the regions, and it is even less clear that the added complexity and cost in coupling regions is worth the effort. Present fluid and kinetic codes treat the SOL as one region, typically with a non-uniform mesh along the magnetic field that is larger near the less collisional midplane and much smaller near the divertor plates.

16. What is the minimum PMI wall model required for providing the boundary conditions for the SOL/boundary region

Any SOL/divertor code modeling normal steady operation needs to include a particle-recycling model at material surfaces where incident ion/electron pairs are re-injected into the system as neutrals (atoms or molecules) in a specified ratio that can depend on material conditions. Likewise, sputtering of impurity neutrals from walls needs to be included where the impurity flux is proportional to the incident plasma flux and energy as determined by look-up tables for the impurity "yield." These minimal models exist in all SOL codes.

For sputtering erosion and transport of resulting the minimum initial PMI model response is a 2D time-independent output of single-material wall and divertor sputtered surface material fluxes 
at a near-surface boundary (e.g., $5 \mathrm{~cm}$ from the surface, depending on plasma regime) for use as boundary conditions in the plasma edge/SOL codes, and related outputs such as tritium codeposition in re-deposited material. This should be followed by major upgrades including timedependent, 3-D outputs, in particular for "blob" response, and mixed material formation/response.

For the large plasma transient (ELMs, disruptions, runaway electrons, etc.) material response, the minimum initial PMI model is one giving an "acceptable" or "unacceptable" output; e.g., for tungsten a melt or no-melt condition for giant ELMs or other ELMs. This should soon be followed, however, by a much more detailed output involving emitted material radiation and particle fluxes to the SOL, material lifetime, and related parameters.

The next step beyond these models is to include the exposure history of the material to compute the recycling coefficients and sputtering coefficients. At the beginning of a discharge, the material may not be saturated with hydrogen owing to discharge cleaning and thus have a low recycling coefficient. Later in the discharge, the material is saturated giving a one-for-one return of neutral flux to plasma flux. Heating of the surfaces can also change the recycling and sputtering coefficients. There are models developed for these processes with some implementation in existing codes.

\section{Add to introduction a discussion of how the research goals can be linked to solving problems} for the customers

There are many questions/problems related to device design, operation, and physics discovery that a Boundary model can help answer for the most prominent customers on the immediate horizon: present-day devices and ITER. Examples of these questions are:

- What power level can the device operate at to avoid overheating the divertor plates in steady state without ELMs but in the presence of intermittent, blobby transport?

- What size and frequency of ELMs can a given design tolerate?

- Will material mixing in a Be, C, W material divertor/wall system (initial ITER) still yield adequate material properties for operation

- Which wall region does tritium migrate to and can it be adequately removed to keep the inventory below site limits?

- Can a high-powered device operate with tungsten walls/divertor without excessive core impurity contamination?

- What medium-Z impurity gas(es) is(are) optimal to maintain an effective radiative divertor mode?

- Can helium be adequately pumped during DT operation? 